\title{
ELEZIONI LOCALI E DESTRUTTURAZIONE PARTITICA. LA NUOVA LEGGE ALLA PROVA
}

\author{
di Aldo Di Virgilio
}

La vertiginosa accelerazione che, con modalità e accenti propri delle fasi di crisi e transizione di regime, ha investito la politica italiana degli ultimi venti mesi ha conferito alle tornate elettorali del giugno e del novembre-dicembre 1993 un rilievo e un significato politico riconosciuto assai di rado a elezioni comunali e provinciali ${ }^{1}$.

In questa direzione convergevano già dalla vigilia molteplici fattori. I due test elettorali presentavano anzitutto un'indubbia visibilità quantitativa e simbolica. In secondo luogo la maggior parte delle città e delle province era convocata al voto in anticipo rispetto alla scadenza naturale dei propri consigli ${ }^{2}$ a causa di circostanze connesse a vario titolo con la crisi politica nazionale (diretto coinvolgimento di intere amministrazioni locali nelle inchieste giudiziarie connesse alle molte «tangentopoli» venute alla luce

Questo lavoro anticipa alcuni risultati di una ricerca più ampia tuttora in corso di svolgimento. Desidero ringraziare Stefano Bartolini, Roberto D'Alimonte e Paolo Feltrin con cui bo discusso vari aspetti di questo lavoro. Ringrazio inoltre la dott.ssa Paola Menta e la sig.ra Maria Grazia Burattini del Servizio elettorale del Ministero degli Interni per la loro disponibilità nel fornirmi, a più riprese, $i$ dati elettorali.

${ }^{1}$ Fanno eccezione le elezioni amministrative del 1946-1947 e quelle del 1975, in condizioni però del tutto diverse. Mentre le prime risentono infatti della fluidità di un quadro partitico ancora in formazione e «preparano» le elezioni politiche del 1948 (termine $a$ quo del consolidamento democratico e, quindi, della strutturazione del sistema partitico) e le seconde annunciano un (momentaneo) riallineamento, caratterizzato dalla crescita elettorale del Pci e dall'accresciuta concentrazione bipolare del voto, le elezioni in esame si collocano in una fase di dealignment (iniziata nel 1990 e maturata nel 1992) in cui si combinano forte volatilità, destrutturazione partitica e territorializzazione del voto.

${ }^{2}$ Delle 211 città con più di 15.000 abitanti chiamate al voto nelle tornate estiva e autunnale di voto, oltre la metà ha rinnovato il proprio consiglio prima della scadenza naturale. Il numero di comuni commissariati o sottoposti ad altra gestione straordinaria era di 38 (su 112) nella tornata di giugno, fra cui nove capoluoghi di provincia, e di 96 (su 99) nella tornata di novembre-dicembre.

RIVISTA ITALIANA DI SCIENZA POLITICA / a. XXIV, n. 1, aprile 1994 
a cascata negli ultimi mesi; crescita del tasso di litigiosità politica nei partiti e nelle coalizioni locali (anche) a seguito dell'indebolimento delle segreterie partitiche nazionali e della loro presa sulla distribuzione dei posti di governo a livello periferico; conseguente incapacità di provvedere alla formazione delle giunte comunali e provinciali entro i tempi previsti dalla legge e relativo commissariamento amministrativo). A questi fattori politico-congiunturali si aggiungeva poi l'applicazione del nuovo sistema elettorale comunale e provinciale, il quale, modificando le modalità di selezione dei vertici del governo locale e di composizione dei consigli, poneva interrogativi tanto sul versante della competizione elettorale quanto sul piano della qualità e del rendimento del governo locale. La stessa dislocazione temporale delle due tornate elettorali, infine, costituiva una condizione favorevole per cogliere nei comportamenti degli attori (partiti, candidati, elettori) il riflesso del rapido evolversi delle condizioni esterne di carattere generale, da un lato, e, dall'altro, le tracce di eventuali processi di adattamento alle nuove regole.

Questo lavoro si propone di esaminare l'impatto di queste nuove regole di voto sulla struttura della competizione elettorale e di sviluppare alcune considerazioni sui risultati delle due consultazioni. Si tratta di aspetti che dipendono dall'interazione fra le peculiarità del nuovo sistema elettorale, di per sé in grado di modificare vincoli e opportunità di partiti, candidati ed elettori, e le condizioni di applicazione del nuovo sistema, fra le quali, nell'attuale fase di destrutturazione partitica e di forte volatilità, la capacità degli attori di adeguarsi prontamente ai nuovi meccanismi. Alla nuova legge elettorale è destinata la prima sezione. Al riscontro empirico, invece, le sezioni seguenti, in un'analisi circoscritta alle elezioni comunali e, in questo ambito, soprattutto ai comuni più grandi (i 211 centri con più di 15.000 abitanti).

\section{La nuova legge elettorale comunale}

In una fase di ingovernabilità crescente delle amministrazioni locali e incalzato dalla minaccia di una riforma attuata per via referendaria ${ }^{3}$, il Parlamento ha adottato nel marzo 1993 una

${ }^{3} \mathrm{La}$ legge elettorale comunale è stata in due occasioni bersaglio dell'iniziativa referendaria del Comitato per le riforme elettorali promosso dall'on. Segni. Una prima richiesta, depositata in Cassazione nel febbraio 1990, era stata giudicata inammissibile. 
nuova normativa elettorale per comuni e province ${ }^{4}$. Il testo di legge, oltre a modificare il sistema elettorale in senso stretto struttura del voto, traduzione dei voti in seggi, scelte rese disponibili all'elettores -, interviene anche sull'insieme delle disposizioni di contorno e, soprattutto, incide sui rapporti fra sindaco, giunta e consiglio e, quindi, sulla forma (locale) di governo.

Il principale aspetto innovativo introdotto dalla legge è l'elezione diretta del sindaco (e del presidente del consiglio provinciale) ${ }^{6}$. Ad essa si collegano misure che accrescono, non soltanto per effetto del meccanismo elettorale, l'autonomia degli organi esecutivi e garantiscono la stabilità del governo municipale. La legge n. 81 differenzia con maggior chiarezza fra ruoli di governo (il sindaco e la sua giunta) e ruoli di controllo (il consiglio) e garantisce così al sindaco (demo-eletto) un margine

La Corte costituzionale (sentenza n. 47/1991: Giorgis 1992) vi aveva infatti ravvisato un vizio di eterogeneità in quanto il ritaglio abrogativo proposto contemplava al tempo stesso l'abolizione della soglia demografica che limitava il sistema maggioritario ai comuni con meno di 5.000 abitanti e l'eliminazione del panachage, materie sulle quali si potevano avere opinioni discordanti. Nella seconda richiesta i promotori avevano circoscritto la richiesta referendaria al primo punto, ottenendo il giudizio di ammissibilità della Corte (sentenza n. 33/1993). La relativa consultazione referendaria era stata così convocata per il 18 aprile 1993 e il suo prevedibile esito positivo avrebbe esteso a tutti i comuni il sistema elettorale fino a quel momento vigente nei centri con meno di 5.000 abitanti. Con una decisione condivisa solo in parte dal Comitato promotore, la Cassazione ha poi ritenuto la nuova legge elettorale, votata dal Parlamento il 25 marzo 1993, sufficiente a cancellare la prevista consultazione referendaria.

${ }_{4}^{4}$ Si tratta della legge n. 81 del 25 marzo 1993 che reca norme per l'«Elezione diretta dei sindaci, del presidente della provincia, del consiglio comunale e del consiglio provinciale» e che modifica il dpr n. 570 del 16 maggio 1960 («Testo unico delle leggi per la composizione e la elezione degli organi delle Amministrazioni comunali») e successive integrazioni (in particolare la legge n. 633 del 10 agosto 1964).

5 Nessuna modifica è invece intervenuta in merito alla configurazione delle circoscrizioni. In particolare, il territorio comunale resta indiviso anche nel caso delle città metropolitane, di cui era stato richiesto da più parti il ritaglio in circoscrizioni d'arrondissement.

6 Pressoché sconosciuta negli ordinamenti europei (per una rassegna di casi nazionali, cfr. Gambino 1991 e Riccamboni 1992) e poco praticata anche negli Stati Uniti, l'elezione diretta del sindaco ha costituito la principale istanza propositiva (accanto alla propensione maggioritaria espressa per via abrogativa) del movimento referendario guidato dall'on. Segni. All'investitura popolare del sindaco il movimento referendario attribuiva molteplici obiettivi quali: il conseguimento di una partecipazione più responsabile in grado di riavvicinare amministrazione comunale e cittadinanza; l'identificazione di un luogo di imputazione di responsabilità politica più certo e visibile, nella misura in cui al sindaco demo-eletto si accompagnasse una coesa compagine maggioritaria nel consiglio (anche se il «doppio voto», fortemente voluto da Segni, arriva a vanificare in alcuni casi proprio questa condizione); la sperimentazione di una prassi di cui si auspicava l'estensione anche al livello nazionale (attraverso l'elezione diretta del premier). 
di manovra assai più ampio che in passato (Barbera 1993). In virtù della sua legittimazione diretta, e autonoma dal consiglio, il sindaco, ad esempio, assume in proprio il potere di nomina e di revoca degli assessori. Ciò gli consente di costruire la propria «squadra» di governo, anziché esserne per lo più la risultante e doverne subire $\mathrm{i}$ condizionamenti come per il passato. D'altro canto, l'incompatibilità fra carica di assessore e carica di consigliere (limitata ai comuni con più di 15.000 abitanti) e, soprattutto, la norma secondo cui l'approvazione di una mozione di sfiducia nei confronti del sindaco comporta, assieme alle dimissioni di quest'ultimo, anche il rinnovo del consiglio comunale mediante nuove elezioni, convergono verso l'obiettivo della stabilità. Tutto ciò disancora gli assetti e il profilo del governo locale dal modello proporzionale-assembleare fin qui prevalente e segnala una continuità, se non una complementarietà, fra la legge n. 81 e la legge n. 142 del 18 giugno 1990 di riordino delle autonomie locali?

Questo nuovo quadro di rapporti fra sindaco, giunta e consiglio si accompagna alla modifica di alcune disposizioni di contorno. Il mandato elettorale (del sindaco e del consiglio) è, ad esempio, ridotto di un anno (da cinque a quattro), mentre il sindaco (e gli assessori) che abbiano completato due mandati consecutivi non sono immediatamente rieleggibili. La legge prevede inoltre la riduzione del numero complessivo dei consiglieri comunali di circa un quinto e una leggera crescita del numero complessivo degli assessori, che si riduce però di oltre un quarto nelle città con più di 100.000 abitanti (tab. 1) $)^{8}$ Questi muta-

${ }^{7}$ A riguardo si deve ricordare che la legge n. 142/1990 aveva (a) rovesciato il precedente schema di ripartizione delle attribuzioni tra consiglio e giunta, sottraendo al consiglio la «competenza generale/residuale» e attribuendola alla giunta; (b) introdotto l'istituto della «sfiducia costruttiva», rimasto per lo più lettera morta a causa della natura quasi sempre extraconsiliare delle crisi di giunta; (c) fissato un termine di sessanta giomi per l'elezione del sindaco e della giunta, allo scadere del quale, per l'impossibilità di assicurare il normale funzionamento degli organi e dei servizi, il consiglio decade dalle proprie funzioni con conseguente ricorso a nuove elezioni. Su questi punti, e più in generale sul contenuto della legge n. 142, si veda Vandelli (1990).

${ }_{8}$ È opportuno rendere esplicite le eccezioni al rapporto fra numero dei seggi e dimensione demografica dei comuni che determinano nella tab. 1 alcune discordanze di riga. Ai comuni capoluogo di provincia con meno di 100.000 abitanti (si tratta di 54 dei 240 comuni della classe demografica 30.001-100.000 abitanti) spettano, ad esempio, 40 seggi (50 secondo la vecchia legge) anziché $30(40)$. La legge regionale n. 16 del 1963 attribuiva ai comuni siciliani con popolazione compresa fra i 15.001 e i 30.000 abitanti un consiglio di 32 seggi anziché di 30. Con la legge regionale n. 26 del 1993 - e quindi a partire dalle elezioni del novembre-dicembre - anche in Sicilia il consiglio di tali comuni è di 
TAB. 1. Distribuzione dei comuni in classi demografiche. Numero complessivo dei consiglieri e degli assessori comunali prima e dopo la riforma elettorale

\begin{tabular}{|c|c|c|c|c|c|c|c|c|c|c|}
\hline \multirow[t]{2}{*}{ Classe demografica } & \multicolumn{2}{|c|}{ Unità } & \multicolumn{2}{|c|}{ Seggi } & \multicolumn{2}{|c|}{ Assessori } & \multicolumn{2}{|c|}{ Consiglieri } & \multicolumn{2}{|c|}{ Assessori. } \\
\hline & n. & $\%$ & 1993 & 1963 & 1993 & 1963 & 1993 & 1963 & 1993 & 1963 \\
\hline 10 a 3.000 & 4.680 & 57,8 & 12 & 15 & 2 & 2 & 57.015 & 70.200 & 9.930 & 9.360 \\
\hline da 3.001 a 10.000 & 2.381 & 29,4 & 16 & 20 & 4 & 4 & 38.090 & 47.620 & 9.610 & 9.524 \\
\hline da 10.001 a 15.000 & 406 & 5,0 & 20 & 30 & 6 & 4 & 8.170 & 12.180 & 2.456 & 1.634 \\
\hline da 15.001 a 30.000 & 347 & 4,3 & 20 & 30 & 6 & 4 & 6.960 & 10.484 & 2.090 & 1.392 \\
\hline da 30.001 a 100.000 & 240 & 2,9 & 30 & 40 & 6 & 6 & 7.750 & 10.100 & 1.452 & 1.446 \\
\hline da 100.001 a 250.000 & 34 & 0,4 & 40 & 50 & 8 & 10 & 1.370 & 1.700 & 274 & 34 \\
\hline 250.001 a 500.000 & 6 & 0,1 & 46 & 60 & 8 & 12 & 275 & 360 & 48 & \\
\hline da 500.001 a 1.000 .000 & 3 & 0,05 & 50 & 80 & 8 & 14 & 150 & 240 & 24 & \\
\hline oltre 1.000 .000 & 3 & 0,05 & 60 & 80 & 8 & 14 & 180 & 240 & 24 & 42 \\
\hline Italia & 8.100 & 00,0 & & & & & 119.960 & 153.124 & 25.908 & 23.852 \\
\hline
\end{tabular}

Fonti: Elaborazione da Istat (1993) e legge 81/1993 e 633/1964. Per i comuni di Sicilia e Trentino-Alto Adige, regioni che in materia elettorale hanno competenze proprie, legge regionale 16/1963 e 26/1993 nel primo caso e legge regionale 5/1956 e 1/1993 nel secondo.

menti non mancheranno di influire sulla struttura delle carriere politiche di livello locale, e in particolare sul loro grado di esclusività rispetto ad altri percorsi professionali e sul loro nesso con carriere politiche di altro livello (regionale o nazionale). Per apprezzare la portata di tali evoluzioni si dovrà attendere la disponibilità di un riscontro empirico di medio periodo. È però possibile ipotizzare fin d'ora che la maggiore visibilità conseguita dal sindaco attraverso l'investitura diretta potrà estenderne l'influenza, soprattutto in una prospettiva di localizzazione della classe politica parlamentare, pur senza trasformarlo (per il quadro di incompatibilità previsto dalla legge) in un maire-deputé

30 membri, mentre i comuni dell'isola con popolazione compresa fra i 3.001 e i 10.000 abitanti hanno un consiglio di 15 membri (anziché 16) e i comuni con popolazione compresa fra i 250.000 e i 500.000 (Catania) hanno un consiglio di 45 membri (anziché 46). Nei comuni del Trentino-Alto Adige è tuttora vigente la composizione dei consigli precedente l'entrata in vigore della legge $n$. 81. Quanto al numero di assessori, $i$ comuni del Trentino-Alto Adige con popolazione compresa fra i 10.001 e i 30.000 abitanti potevano avere fino a un massimo di sei assessori, quelli con popolazione compresa fra i $30.001 \mathrm{e} \mathrm{i}$ 100.000 fino a un massimo di otto (legge regionale n. 5/1956 e successive integrazioni e modifiche). Dal gennaio 1993, il numero massimo di assessori è passato, nella regione Trentino-Alto Adige, a quattro per $i$ comuni fino a 3.000 abitanti, a sei per $i$ comuni fino a 10.000 abitanti e a dieci per gli altri comuni (legge regionale n. 1/1993). 
sul modello transalpino. Meno definibile $a$ priori appare invece il profilo del nuovo assessore, libero da responsabilità di natura elettorale e vincolato unicamente al diretto rapporto fiduciario col sindaco, il quale tenderà, presumibilmente, a utilizzarne le specifiche risorse e competenze «civili».

Molte di queste innovazioni, che pure lasciano irrisolti alcuni nodi tradizionali del governo locale - dal raccordo fra sindaco-politico e sindaco-amministratore, alla mancata diversificazione della forma del governo municipale e dello stesso ruolo del sindaco al mutare della dimensione demografica del comune (Cammelli 1993) - si innestano sul mutamento del sistema elettorale in senso stretto.

Come per il passato, le modalità di voto si differenziano in base alla classe demografica dei comuni. L'applicazione del principio maggioritario, fin qui limitata ai comuni con meno di 5.000 abitanti, viene ora estesa alle amministrazioni con popolazione fino a 15.000 abitanti'. L'innalzamento della soglia pone sotto regime maggioritario più dei quattro quinti dei comuni italiani, pari a oltre il $40 \%$ della popolazione complessiva ${ }^{10}$. In tali comuni ciascuna lista di candidati al consiglio è collegata a un candidato-sindaco. Col proprio voto l'elettore esprime una doppia scelta, che vale sia per eleggere il sindaco sia per la lista collegata al candidato-sindaco prescelto. All'interno di tale lista, l'elettore può indicare altresì un (unico) voto di preferenza.

Il candidato che ottiene il maggior numero di voti viene eletto alla mayorship. La lista ad esso collegata si aggiudica i due terzi dei seggi. Il restante terzo viene ripartito proporzionalmente, con divisore d'Hondt, fra le altre liste. L'elezione dei consiglieri segue l'ordine delle preferenze e poi l'ordine di lista, fatta salva l'attribuzione del primo seggio ottenuto dalle liste di opposizione ai candidati alla carica di sindaco risultati perdenti.

La nuova legge elettorale configura così, per i comuni più piccoli, un sistema elettorale di tipo misto, maggioritario con rappresentanza proporzionale delle minoranze. Si tratta di un meccanismo che differisce in più punti rispetto a quello prece-

9 Si tratta di un'evoluzione in controtendenza rispetto alle precedenti modifiche dell'ordinamento elettorale locale. Il principio maggioritario, utilizzato nel 1946 nei comuni con meno di 30.000 abitanti, venne limitato nel 1956 ai comuni con meno di 15.000 abitanti e circoscritto poi dal 1964 ai comuni con meno di 5.000 abitanti (Agosta 1992).

${ }^{10}$ Come si può ricavare dai dati Istat (1993), si tratta di 7.467 comuni su 8.100 e di 23.717.709 abitanti su 56.778.031. 
dente, poiché riduce il quantum del premio maggioritario dai $4 / 5$ ai $2 / 3$ dei seggi, consente la presenza in consiglio di più opposizioni anziché di un'unica minoranza, elimina il panachage.

Più articolata, e assai meno lineare, si presenta la nuova normativa elettorale nel caso dei centri maggiori, i 633 comuni con oltre 15.000 abitanti. Anche in questi comuni l'arena esecutiva (la scelta del sindaco) e l'arena rappresentativa (la scelta per il consiglio) sono arene interdipendenti. Si tratta però, al tempo stesso, di arene disgiunte. Il collegamento fra candidatosindaco e lista di candidati-consiglieri non è biunivoco come nel caso precedente: ad uno stesso candidato-sindaco possono infatti collegarsi più liste, le quali, al di là di questa convergen$\mathrm{za}$, restano fra loro in competizione sul terreno consiliare. L'elettore, dal canto suo, ha a disposizione un doppio voto che può utilizzare secondo tre modalità principali: $(a)$ scegliere uno dei candidati alla carica di sindaco senza esprimere alcuna opzione di lista; $(b)$ votare soltanto per una lista senza esprimere alcuna opzione per il sindaco, scelta conteggiata anche come voto a favore del candidato-sindaco collegato alla lista prescelta; (c) esprimere un voto diviso e quindi un'opzione disgiunta: per un candidato-sindaco e per una lista fra loro non collegati. L'elettore può attribuire, inoltre, un (unico) voto di preferenza per uno dei candidati-consiglieri della lista prescelta.

Questo ampio ventaglio di possibilità di scelta ha inteso affermare la preminenza dell'elezione del sindaco, al di là di vincoli di lista o di partito, e dare parziale soddisfazione alla dichiarata preferenza del movimento referendario per la doppia scheda. Nell'operatività del nuovo sistema elettorale esso induce peraltro una variabilità di esiti, non sempre coerenti con $\mathrm{i}$ due principali obiettivi attribuiti alla nuova legge: garantire stabilità e autonomia al governo locale; limitare il grado di frammentazione della rappresentanza politica municipale. L'elemento decisivo, lo si è già detto, è l'elezione del sindaco, che risulta quasi sempre (ma non sempre) determinante rispetto alla composizione del consiglio.

Per tutti i comuni con oltre 15.000 abitanti, la formula della vittoria è costituita dalla maggioranza assoluta dei voti validi. Se uno dei candidati la consegue, la distribuzione dei seggi al consiglio prevede due possibilità: (a) la lista o la coalizione di liste che ha sostenuto la candidatura vincente ha anch'essa superato la soglia del $50 \%$ dei voti validi, e allora si vede attribuito, qualora non l'abbia conquistato con le sue proprie forze elettorali, 
il $60 \%$ dei seggi; (b) la lista o la coalizione di liste che ha sostenuto la candidatura vincente si ferma al di sotto del $50 \%$ dei voti validi, e allora l'attribuzione dei seggi alle liste avviene, come per il passato, su base proporzionale (divisore d'Hondt).

Se nessun candidato-sindaco ottiene la maggioranza assoluta dei voti validi, si procede a un turno di ballottaggio «chiuso» ai due candidati meglio piazzati. Ad essi è consentito, nella prima delle due settimane che intercorrono fra primo e secondo turno, di allargare il campo dei propri sostenitori collegandosi con liste i cui candidati alla carica di sindaco siano stati eliminati. Sempreché nessun'altra lista o coalizione di liste abbia superato al primo turno il $50 \%$ dei voti validi, alla lista o coalizione collegata al sindaco eletto viene attribuito il $60 \%$ dei seggi. Il restante $40 \%$ viene assegnato su base proporzionale (divisore d'Hondt) alle altre liste. L'elezione dei consiglieri segue l'ordine delle preferenze e poi l'ordine di lista, fatta salva l'attribuzione del primo seggio ottenuto dalle liste o coalizioni di opposizione - in quest'ultimo caso fuori quota rispetto alle singole componenti - ai candidati alla carica di sindaco risultati perdenti.

$\mathrm{Ne}$ risulta un sistema elettorale misto a formula variabile: proporzionale, con premio di maggioranza eventuale ${ }^{11}$. Tale sistema presenta non pochi aspetti controversi, a volte in evidente bisticcio rispetto agli obiettivi più sopra menzionati.

La possibilità di ricombinare le alleanze fra un turno e l'altro, ad esempio, permette a una piccola lista, sconfitta al primo turno ma capace di aggregarsi alla candidatura vincente nel turno di ballottaggio, di godere del premio maggioritario e di ottenere più seggi di quanti non ne avrebbe ottenuti alleandosi fin dal primo turno con una lista già forte ma perdente, e ciò scoraggia le spinte aggregative. È però soprattutto sul versante dei rapporti fra esecutivo (sindaco e giunta) e consiglio che possono verificarsi gli esiti più paradossali. Le concrete modalità di funzionamento del nuovo congegno elettorale dipendono dal modo in cui l'andamento della competizione nell'arena esecutiva e la distribuzione dei consensi nell'arena rappresentativa si combinano fra loro. Il punto è che tale combinazione è, almeno in parte, accidentale. La possibilità che il sindaco possa contare

1 Un tipo ancora diverso di sistema elettorale, intermedio fra il sistema utilizzato nei piccoli comuni (quelli al di sotto dei 15.000 abitanti) e quello utilizzato nei centri maggiori (i comuni con più di 15.000 abitanti), è quello prescritto dalla legge $n .81$ per l'elezione del presidente della provincia e del consiglio provinciale. 
su una maggioranza consiliare a lui favorevole - esito di gran lunga prevalente alla prova del riscontro empirico costituito dalle elezioni comunali del giugno e del novembre-dicembre 1993 - è soltanto una delle possibilità. Al sindaco potrebbe infatti accadere di coabitare con una maggioranza consiliare coesa e a lui ostile (quando una lista o coalizione avversaria a quella del candidato-sindaco poi eletto ottiene al primo turno la maggioranza assoluta dei voti validi) o con un consiglio privo di maggioranza precostituita (quando il sindaco viene eletto al primo turno, ma la lista o coalizione che lo sostiene non ottiene la maggioranza assoluta dei voti validi).

Cas de figure di questo tipo - già verificatisi nell'applicazione concreta $^{12}$ - consentono di fissare alcune modalità operative controverse e paradossali del nuovo congegno elettorale. L'applicazione del meccanismo maggioritario, ad esempio, diventa più probabile in un quadro competitivo multipolare anziché bipolare (e quindi anche se le candidature sono sostenute da alleanze non troppo estese). Un candidato alla carica di sindaco in grado di attrarre consensi a tutto campo, d'altro canto, potrebbe essere penalizzato proprio da questa sua personale capacità aggregativa $\mathrm{e}$ restare privo di maggioranza in consiglio, una volta ottenuta l'elezione al primo turno, proprio a causa della sua «eccessiva» popolarità. Il legislatore, tutto sommato, avrebbe fatto meglio a evitare l'ibrido dell'interdipendenza fra le arene in presenza di una possibile scelta disgiunta, che induce gli attori a seguire «comportamenti strategici» orientati, ad esempio, a vanificare l'attribuzione del premio maggioritario (Vassallo 1993, 66-75), e a percorrere strade diverse. Soluzioni quali il voto doppio adottato per i piccoli comuni, che consentirebbe, peraltro, anche di mutuare aspetti del doppio turno municipale in vigore in Francia dal 1983 (Di Virgilio 1992), oppure l'adozione di una scelta (presidenzialista) di completa indipendenza fra opzione esecutiva e opzione rappresentativa avrebbero evitato il possibile verificarsi di inconvenienti come quelli appena descritti.

Non costituisce invece una valida alternativa la soluzione -

12 Nella tornata estiva, ad esempio, ad Arzano (Na) e a Marcianise (Ce) il sindaco è stato eletto al primo turno, ma la coalizione che lo sosteneva è rimasta al di sotto della maggioranza dei voti validi. Ad Aversa (Ce), Maglie (Le) e Martina Franca (Ta) il sindaco eletto al ballottaggio - negli ultimi due casi con quasi il $70 \%$ dei voti validi - è rimasto privo di maggioranza al consiglio poiché la coalizione che sosteneva il candidato-sindaco sconfitto al ballottaggio aveva ottenuto al primo turno la maggioranza assoluta dei voti. 
«presidenzialista», ma entro un assetto sostanzialmente «parlamentare» - adottata dalla regione Sicilia, la cui nuova legge elettorale comunale, utilizzata anch'essa per la prima volta nel giugno 1993, differisce per molti aspetti dalla normativa nazionale ${ }^{13}$. Più specificamente, la scelta per il sindaco e la scelta per il consiglio si presentano, appunto, come opzioni del tutto separate, rispetto alle quali l'elettore si pronuncia su due schede distinte. L'elezione a sindaco richiede in tutti i casi, a prescindere dalla dimensione demografica del comune, il conseguimento della maggioranza assoluta dei voti validi e prevede l'eventuale ricorso a un ballottaggio «chiuso» ai due candidati meglio piazzati dopo il primo turno. Per quanto riguarda l'elezione del consiglio, nei comuni con meno di 15.000 abitanti (10.000 fino al settembre 1993 e quindi anche nella tornata elettorale di giugno) la lista col maggior numero di voti ottiene i due terzi dei seggi, mentre alla minoranza più forte è attribuito il restante terzo. Nei comuni con oltre 15.000 abitanti, invece, il $70 \%$ dei seggi viene assegnato con metodo proporzionale (divisore d'Hondt), mentre del restante $30 \%$ due terzi sono attribuiti alla lista o coalizione di liste collegate (che abbiano cioè sottoscritto una dichiarazione programmatica comune) maggioritaria e un terzo alla lista o coalizione seconda per numero di voti validi. Alla vigilia dell'eventuale turno di ballottaggio, la distribuzione dei seggi al consiglio è quindi già nota. Ciò può orientare in senso strategico la condotta di secondo turno degli esclusi. Una forza destinata a diventare opposizione condizionante può, ad esempio, auspicare e agevolare la vittoria del candidato più debole (sul caso di Catania, si veda Motta e Lanza 1993). Ma è soprattutto l'assai probabile proporsi delle condizioni del governo (locale) «diviso» a suscitare le maggiori perplessità sugli effetti che la nuova legge elettorale comunale siciliana potrà determinare ${ }^{14}$.

${ }_{13}$ Si tratta della legge regionale 26 agosto $1992, \mathrm{n} .7$ che reca «Norme per l'elezione con suffragio popolare del sindaco. Nuove norme per l'elezione dei consigli comunali, per la composizione degli organi collegiali dei comuni, per il funzionamento degli organi provinciali e comunali e per l'introduzione della preferenza unicas, a cui la legge regionale 1 settembre $1993, \mathrm{n}$. 26 ha apportato modifiche e integrazioni. La nuova normativa modifica la legge regionale 15 marzo 1963 , n. 16 su l'«Ordinamento amministrativo degli Enti Locali nella Regione siciliana».

${ }_{14}$ E su questo punto che l'assetto presidenzialista viene meno. Al consiglio è infatti consentito, una sola volta nel quadriennio, di promuovere una consultazione popolare sulla rimozione del sindaco. L'accoglimento della proposta determina la decadenza del sindaco (cui segue lo svolgimento di nuove elezioni e l'investitura di un sindaco che resta in carica per portare a compimento il mandato lasciato vacante). Se la consultazione 
La nuova legge elettorale comunale configura, insomma, un meccanismo di voto assai complesso, non privo di incoerenze e di qualche punto oscuro ${ }^{15}$, che comporta per elettori, candidati e partiti un complesso problema di apprendimento e di adattamento. Nelle sezioni che seguono tale problema e il suo intrecciarsi con una congiuntura caratterizzata - lo si è già detto - da destrutturazione partitica $\mathrm{e}$ forte volatilità vengono presi in esame alla luce delle tornate elettorali del giugno e del novembredicembre 1993 in cui per la prima volta il nuovo sistema elettorale ha trovato applicazione. Il riscontro empirico si articola in quattro passaggi. Il primo fissa alcune peculiarità del contesto che ha tenuto a battesimo il nuovo sistema elettorale. Il secondo passaggio esamina invece la struttura dell'offerta elettorale e, più specificamente, le alleanze costituitesi in vista dell'elezione diretta dei sindaci. Segue un confronto dei comportamenti e dei risultati nelle due arene e infine, come quarto e ultimo passaggio, un'analisi del turno di ballottaggio.

\section{Un test non rappresentativo}

L'insieme dei comuni in cui si è votato nel giugno e nel novembre-dicembre 1993 costituisce un campione cospicuo, sia per numero di unità amministrative sia per quota di popolazione amministrata, dell'universo dei comuni italiani.

Il punto da fermare subito è che tale insieme non costituisce da nessun punto di vista un campione di tipo statistico e che, quindi, qualsiasi estrapolazione generalizzante non adeguatamente ponderata indurrebbe un effetto ottico distorsivo dovuto all'assortimento dei comuni chiamati alle urne ${ }^{16}$. Più speci-

dà invece esito negativo è il consiglio a decadere, sostituito da un nuovo consiglio, che resta in carica fino alla scadenza del mandato del sindaco.

${ }^{15}$ È il caso della (più che opinabile) quota di genere «suggerita» dagli artt. 5.2 e 7.1 della legge n. 81 secondo cui «(...) Nelle liste dei candidati nessuno dei due sessi può essere di norma [sic!] rappresentato in misura superiore ai due terzi». La legge $n$. 415 del 15 ottobre 1993 («Modifiche ed integrazioni alla legge 25 marzo 1993, n. 81, sull'elezione diretta del sindaco, del presidente della provincia, del consiglio comunale e del consiglio provinciale») ha chiarito il punto, stabilendo che, per i comuni con meno di $15.000 \mathrm{abi}$ tanti, «(...) Nelle liste dei candidati nessuno dei due sessi può essere rappresentato in misura superiore ai tre quarti dei consiglieri assegnati» (art. 2.1) e che, per i comuni con oltre 15.000 abitanti, «(...) Nelle liste dei candidati nessuno dei due sessi può essere rappresentato in misura superiore ai due terzi dei consiglieri assegnati» (art. 2.2).

${ }_{16}$ Questa minima nota di cautela è stata ampiamente negletta dai mezzi di infor- 
ficamente, l'insieme dei comuni considerati sottorappresenta largamente le unità amministrative più piccole rispetto a quelle con oltre 15.000 abitanti (il rapporto fra le une e le altre è pari a uno a 12 nell'intero universo ed è invece di uno a sette nei 1.606 comuni chiamati alle urne) e, fra quest'ultime, sovrarappresenta i capoluoghi di provincia e, soprattutto, i grandi centri urbani (i 211 centri con oltre 15.000 abitanti chiamati alle urne rappresentano esattamente un terzo dell'intero universo, ma tutte le grandi città, ad eccezione di Firenze, Bologna e Bari, hanno rinnovato fra l'estate e l'autunno i propri organismi rappresentativi e di governo). Squilibri di questo tipo risultano assai più accentuati qualora si assuma a criterio di riferimento il quantum di popolazione amministrata. Lo skew distributivo dovuto all'incidenza delle grandi città finisce infatti col caratterizzare l'elettorato chiamato alle urne come un elettorato essenzialmente urbano e metropolitano, aspetto questo di cui si deve tenere debito conto in sede di analisi.

A fini analitici, come risulta dalla tab. 2, si è disaggregato l'insieme dei comuni andati al voto in tre classi: (a) comuni capoluogo di provincia; (b) comuni non capoluogo; $(c)$ comuni maggioritari. Al più immediato criterio di «rilevanza», quello della soglia demografica (comuni sopra/sotto i 100.000 abitanti), normalmente correlato a comportamenti socio-politici differenziati, si è preferito il criterio dello status amministrativo (comuni capoluogo/non-capoluogo) per ragioni relative alla distribuzione dei casi nelle classi. Le classi «amministrative» risultano infatti meno eterogenee di quelle «demografiche» rispetto alla distribuzione territoriale dei casi.

Il grado di rappresentatività di ciascuna classe nei confronti del proprio universo è riportato nella tab. 3 . La classe $(a)$ è la meno numerosa (33 casi), ma al tempo stesso la più rappresentativa, sia per unità che per quantum di popolazione amministrata. E la meno diseguale in termini di distribuzione territoriale dei casi, salvo una certa sovrarappresentanza dei capoluoghi del Mezzogiorno. Si presenta invece piuttosto eterogenea dal punto di vista demografico, con un range che spazia da Belluno (35.572 abitanti) a Roma (2.775.250 abitanti). A fianco di quindici capoluoghi con meno di 100.000 abitanti vi figurano i sei

mazione che hanno per lo più amplificato aspetti parziali della competizione (in particolare il voto nei grandi centri urbani), inferendo da essi considerazioni di carattere generale in non pochi casi deformanti e prive di fondamento. 
TАВ. 2a. Distribuzione dei comuni chiamati al voto nel giugno e nel novembre-dicembre 1993. Aggregazione per sistema elettorale, per tipo di comune e per zona geografica

\begin{tabular}{|c|c|c|c|c|c|c|c|c|c|c|c|c|c|c|c|}
\hline & \multicolumn{3}{|c|}{ Nord } & \multicolumn{3}{|c|}{ Centro } & \multicolumn{3}{|c|}{ Sud } & \multicolumn{3}{|c|}{ Isole } & \multicolumn{3}{|c|}{ Italia } \\
\hline & I & II & tot. & I & II & tot. & I & II & tot. & I & II & tot. & $\mathrm{I}$ & II & tot. \\
\hline $\begin{array}{l}\text { (a) comuni capoluogo } \\
\text { (b) comuni non capoluogo } \\
\text { (a) }+ \text { (b) }\end{array}$ & $\begin{array}{r}8 \\
18 \\
26\end{array}$ & $\begin{array}{r}6 \\
31 \\
37\end{array}$ & $\begin{array}{l}14 \\
49 \\
63\end{array}$ & $\begin{array}{r}4 \\
23 \\
27\end{array}$ & $\begin{array}{r}3 \\
7 \\
10\end{array}$ & $\begin{array}{r}7 \\
30 \\
37\end{array}$ & $\begin{array}{l}- \\
41 \\
41\end{array}$ & $\begin{array}{r}8 \\
21 \\
29\end{array}$ & $\begin{array}{r}8 \\
62 \\
70\end{array}$ & $\begin{array}{r}2 \\
16 \\
18\end{array}$ & $\begin{array}{r}2 \\
21 \\
23\end{array}$ & $\begin{array}{r}4 \\
37 \\
41\end{array}$ & $\begin{array}{r}14 \\
98 \\
112\end{array}$ & $\begin{array}{l}19 \\
80 \\
99\end{array}$ & $\begin{array}{r}33 \\
178 \\
211\end{array}$ \\
\hline (c) comuni maggioritari & 395 & 70 & 464 & 128 & 28 & 157 & 375 & 130 & 505 & 182 & 97 & 280 & 1.080 & 3251 & .405 \\
\hline
\end{tabular}

I: tornata elettorale del 6 e del 20 giugno 1993.

II: tornata elettorale del 21 novembre e del 5 dicembre 1993.

TAB. 2b. Distribuzione della popolazione interessata alle elezioni comunali del giugno e del novembre-dicembre 1993. Aggregazione per sistema elettorale, per tipo di comune e per zona geografica

\begin{tabular}{lcrrrr}
\hline & Nord & Centro & Sud & Isole & Italia \\
\hline (a) comuni capoluogo & 4.186 .756 & 3.177 .940 & 1.835 .947 & 1.141 .964 & 10.342 .607 \\
(b) comuni non capoluogo & 1.479 .406 & 827.733 & 2.005 .872 & 1.076 .437 & 5.389 .448 \\
(a) + (b) & 5.666 .162 & 4.055 .673 & 3.841 .819 & 2.218 .301 & 15.732 .055 \\
(c) comuni maggioritari & 1.776 .462 & 690.788 & 2.153 .505 & 1.139 .719 & 5.750 .474 \\
\hline
\end{tabular}


comuni italiani con oltre mezzo milione di abitanti (Roma, Milano, Napoli, Torino, Palermo e Genova), sottoinsieme quest'ultimo che coincide col proprio universo e a cui, per alcuni aspetti dell'analisi, si farà riferimento in quanto tale. La classe (b), quella dei centri non capoluogo con popolazione superiore ai 15.000 abitanti (178 casi), comprende comuni con popolazione inferiore a 100.000 abitanti, con l'unica eccezione di Torre del Greco. La sua suddivisione geografica segnala la vistosa sovrarappresentanza dei comuni siciliani e una presenza ben al di sotto della media di comuni del nord del paese. La classe $(c)$, infine, comprende le 1.405 unità con meno di 15.000 abitanti chiamate alle urne nelle due tornate in esame. Nelle pagine che seguono si farà riferimento ad esse solo per alcune delle dimensioni analitiche considerate.

Oltre al fattore demografico e alle suddivisioni territoriali, nel controllo analitico si terrà sotto controllo una terza, importante dimensione: la prospettiva diacronica, cruciale nella valutazione dei processi di apprendimento delle nuove regole elettorali da parte degli attori e di adattamento ad esse.

TAB. 3a. Percentuale di comuni interessati alle elezioni comunali del giugno e del novembre-dicembre 1993 rispetto al totale nazionale. Aggregazione per tipo di sistema elettorale, per tipo di comune e per zona geografica

\begin{tabular}{lccccc}
\hline & Nord & Centro & Sud & Isole & Italia \\
\hline (a) comuni capoluogo & 33.3 & 35.0 & 38.1 & 30.8 & 34.4 \\
(b) comuni non capoluogo & 24.4 & 28.6 & 37.6 & 56.1 & 33.1 \\
(a) + (b) & 25.9 & 29.6 & 37.6 & 51.9 & 33.3 \\
(c) comuni maggioritari & 10.8 & 17.8 & 31.5 & 40.7 & 18.8 \\
\hline
\end{tabular}

TAB. 3b. Percentuale di popolazione interessata alle elezioni comunali del giugno e del novembre-dicembre 1993 rispetto al totale nazionale. Aggregazione per tipo di sistema elettorale, per tipo di comune e per zona geografica

\begin{tabular}{lccccc}
\hline & Nord & Centro & Sud & Isole & Italia \\
\hline (a) comuni capoluogo & 57.4 & 69.0 & 58.3 & 54.6 & 60.3 \\
(b) comuni non capoluogo & 25.6 & 27.7 & 40.0 & 55.9 & 34.4 \\
(a) + (b) & 43.7 & 52.7 & 47.1 & 55.2 & 48.0 \\
(c) comu ni maggioritari & 14.4 & 21.7 & 38.2 & 44.1 & 24.3 \\
\hline
\end{tabular}




\section{Alleanze a geometria variabile}

L'applicazione del nuovo sistema elettorale obbliga a riesaminare le modalità abituali di presentazione e di analisi dei dati disponibili e rende problematica non solo la possibilità di confronti diacronici, ma anche la stessa possibilità di confronti sincronici. Ciò vale soprattutto nei comuni con più di $15.000 \mathrm{abi}$ tanti, nei quali l'introduzione del doppio turno («chiuso») per l'elezione del sindaco e il procedere del processo di destrutturazione partitica in atto lasciavano ipotizzare l'adozione di strategie competitive diverse dal passato e una loro più marcata articolazione locale ${ }^{17}$. In termini aggregati, l'applicazione della nuova legge elettorale lasciava inoltre prevedere quattro probabili conseguenze: (a) un impatto riduttivo sulla frammentazione dell'offerta, una differenzialità della struttura dell'offerta $(b) n e i$ casi (per la presenza di due arene distinte), (c) fra i casi (in ragione della presenza/assenza di aggregazioni e della loro probabile diversificazione), ( $d$ ) fra un turno e l'altro (per il possibile ricombinarsi delle alleanze alla vigilia del ballottaggio).

Per poter controllare, in prima approssimazione, le ipotesi della vigilia, si è costruita anzitutto la tab. 4 . Vi è riportato il numero medio di liste concorrenti registrato nelle elezioni in esame e nelle elezioni comunali precedenti, le ultime svoltesi (in una data compresa fra il 1988 e il 1991) con la vecchia legge elettorale, nonché il numero medio di candidature alla carica di sindaco. L'articolazione quantitativa dell'offerta che se ne ricava costituisce, evidentemente, un indicatore ancora rozzo dell'effettivo formato della competizione, su cui influisce in modo decisivo il grado di competitività delle liste concorrenti e, quindi, il risultato. La tab. 4 fornisce ugualmente, tuttavia, alcune significative indicazioni, le quali disattendono, in buona parte, le attese della vigilia ${ }^{18}$. La nuova legge elettorale, ad esempio, non

17 Anche per questo le analisi disponibili sono orientate in prevalenza allo studio di casi singoli (si cfr. l'esame del voto nei principali centri urbani chiamati alle urne nella tornata estiva condotto da Bagnasco (1993), Sani (1993), Verzichelli (1993), Lanza e Motta (1993). Presenta invece un impianto di carattere aggregato il lavoro realizzato da Di Franco e Gritti (1993) presso l'Osservatorio di sociologia elettorale dell'Università di Roma.

18 Attese, a ben guardare, per buona parte infondate, poiché la nuova legge elettorale, sul versante dell'arena rappresentativa, è sostanzialmente priva di meccanismi riduttivi di tipo endogeno (a meno di voler considerare rilevante in tal senso l'innalzamento del numero delle firme necessario per poter presentare una lista di candidati) e 
sembra aver comportato alcun effetto di tipo riduttivo (dalla precedente media complessiva di 8,8 liste concorrenti si passa infatti a 8,7), né sembrano manifestarsi tendenze di questo tipo fra una tornata e l'altra (alla lieve contrazione del numero medio di liste concorrenti registrata in giugno corrisponde, in novembre-dicembre, una maggiore frammentazione). Sull'andamento di questi valori medi influisce soprattutto il fattore demografico (si confrontino i valori relativi ai sei comuni metropolitani), mentre non sembrano esserci significative variazioni di carattere territoriale (salvo forse l'accresciuto sventagliamento dell'offerta nei capoluoghi di provincia del Mezzogiorno).

Più contenuta, com'era ragionevole attendersi in un'arena orientata alla conquista di una carica monocratica e improntata quindi a una logica strettamente maggioritaria, si presenta l'articolazione quantitativa delle candidature alla carica di sindaco (6,5 candidature contro 8,7 liste: si veda ancora la tab. 4). Anche per l'arena esecutiva il dato è solo indicativo dell'effettiva estensione dello spazio competitivo e va «deflazionato» delle candidature marginali. Come nel caso delle liste, si rilevano anche qui differenze legate principalmente alla dimensione demografica dei comuni.

Un quadro in parte diverso emerge, infine, nei comuni maggioritari. Nonostante il numero medio di liste presenti cresca da 2.6 (giugno) a 3.1 (novembre-dicembre), al confronto diacronico l'effetto costrittivo della nuova legge elettorale si manifesta ugualmente, in particolare nei comuni in cui più drastico è stato il cambiamento del sistema elettorale ${ }^{19}$.

Quando dalla cornice aggregata si passa a considerare l'offerta dal punto di vista dei singoli attori, tre domande aiutano a catturare i principali effetti associati all'impiego del nuovo sistema elettorale e/o al procedere del processo di destrutturazione partitica. Si tratta dell'atteggiamento dei partiti tradizionali, della (eventuale) presenza di una «nuova» offerta elettorale, del grado di diffusione e del profilo politico delle aggregazioni costituite a sostegno di candidature alla carica di sindaco.

fonda la sua portata manipolativa sulla retroazione degli (ipotetici) effetti riduttivi indotti dalla competizione per l'elezione del sindaco.

19 Nei dei comuni con popolazione compresa fra i 10.000 e i 15.000 abitanti il numero medio delle liste concorrenti si riduce considerevolmente. A giuno (69 casi) passa da 7.3 (ultime elezioni svoltesi con la proporzionale) a 4.0 (elezioni svoltesi con il maggioritario). A novembre (51 casi) da 7.1 a 4.1. 
TAB. 4. Numero medio di liste concorrenti e numero medio di candidature alla carica di sindaco per tipo di comune e per area geografica e confronto con le ultime elezioni comunali svoltesi con la vecchia legge elettorale

\begin{tabular}{|c|c|c|c|c|c|c|c|c|c|c|c|c|c|c|c|}
\hline & \multicolumn{3}{|c|}{ Nord } & \multicolumn{3}{|c|}{ Centro } & \multicolumn{3}{|c|}{ Sud } & \multicolumn{3}{|c|}{ Isole } & \multicolumn{3}{|c|}{ Italia } \\
\hline & I & II & tot. & I & II & tot. & I & II & tot. & I & II & tot. & I & II & tot. \\
\hline \multicolumn{16}{|l|}{ liste: } \\
\hline $\begin{array}{l}\text { comuni metropolitani } \\
\text { (a) capoluoghi } \\
\text { (b) non capoluoghi } \\
\text { (a) }+ \text { (b) }\end{array}$ & $\begin{array}{c}19,5 \\
11,2 \\
7,9 \\
9\end{array}$ & $\begin{array}{l}17 \\
12,5 \\
8,7 \\
9,4\end{array}$ & $\begin{array}{r}18,5 \\
11,8 \\
8,4 \\
9,2\end{array}$ & $\begin{array}{l}\overline{9,5} \\
8,7 \\
8,8\end{array}$ & $\begin{array}{l}25 \\
18 \\
12,1 \\
13,9\end{array}$ & $\begin{array}{l}25 \\
13,1 \\
9,5 \\
10,2\end{array}$ & $\begin{array}{l}- \\
\overline{7} \\
7\end{array}$ & $\begin{array}{l}17 \\
12,6 \\
7,2 \\
8,7\end{array}$ & $\begin{array}{l}17 \\
12,6 \\
7,1 \\
7,7\end{array}$ & $\begin{array}{l}-\overline{10} \\
8 \\
8,2\end{array}$ & $\begin{array}{l}15 \\
11 \\
8,5 \\
8,7\end{array}$ & $\begin{array}{l}15 \\
10,5 \\
8,3 \\
8,5\end{array}$ & $\begin{array}{r}19,5 \\
10,6 \\
7,7 \\
8,1\end{array}$ & $\begin{array}{r}18,5 \\
13,3 \\
8,6 \\
9,5\end{array}$ & $\begin{array}{r}18,8 \\
12,1 \\
8,4 \\
8,7\end{array}$ \\
\hline $\begin{array}{l}\text { (c) maggioritari } \\
\text { candidature alla } \\
\text { carica di sindaco: }\end{array}$ & 2,8 & 3,7 & 2,9 & 3 & 3,4 & 3,1 & 2,5 & 3,0 & 2,6 & 2,2 & 2,8 & 2,4 & 2,6 & 3,1 & 2,7 \\
\hline $\begin{array}{l}\text { comuni metropolitani } \\
\text { (a) capoluoghi } \\
\text { (b) non capoluoghi } \\
\text { (a) }+ \text { (b) }\end{array}$ & $\begin{array}{l}11 \\
7,6 \\
7 \\
7,2\end{array}$ & $\begin{array}{l}9 \\
7,5 \\
6,5 \\
6,6\end{array}$ & $\begin{array}{r}10,3 \\
7,6 \\
6,7 \\
6,9\end{array}$ & $\begin{array}{l}\overline{8}, 7 \\
7 \\
7,2\end{array}$ & $\begin{array}{l}17 \\
10,7 \\
7,9 \\
8,7\end{array}$ & $\begin{array}{l}- \\
9,6 \\
7,2 \\
7,6\end{array}$ & $\begin{array}{l}- \\
\overline{6} \\
6\end{array}$ & $\begin{array}{l}9 \\
8,4 \\
6,3 \\
6,9\end{array}$ & $\begin{array}{l}9 \\
8,4 \\
6,1 \\
6,4\end{array}$ & $\begin{array}{l}-5 \\
5,9 \\
5,8\end{array}$ & $\begin{array}{l}5 \\
4,5 \\
5 \\
5\end{array}$ & $\begin{array}{l}5 \\
4,7 \\
5,4 \\
5,3\end{array}$ & $\begin{array}{c}11 \\
7,6 \\
6,4 \\
6,6\end{array}$ & $\begin{array}{l}10 \\
8,1 \\
6,2 \\
6,5\end{array}$ & $\begin{array}{r}10,3 \\
7,8 \\
6,3 \\
6,5\end{array}$ \\
\hline
\end{tabular}

liste (ultime elezioni svoltesi con la vecchia legge elettorale):

\begin{tabular}{|c|c|c|c|c|c|c|c|c|c|c|c|c|c|c|c|}
\hline comuni metropolitani & 14,5 & 12 & 13,7 & - & 23 & 23 & - & 12 & 12 & - & 15 & 15 & 14,5 & 15,5 & 15,2 \\
\hline (a) capoluoghi & 11,4 & 12,2 & 11,7 & 9,5 & 14 & 11,4 & - & 10,4 & 10,4 & 10,5 & 11,5 & 11 & 10,7 & 11,6 & 11,2 \\
\hline (b) non capoluoghi & 9,2 & 9,5 & 9,4 & 8,3 & 8,9 & 8,4 & 7,5 & 6,9 & 7,2 & 7,4 & 7,8 & 7,7 & 8 & 8,3 & 8,1 \\
\hline$(a)+(b)$ & 9,9 & 10 & 9,9 & 8,5 & 10,4 & 9 & 7,5 & 7,9 & 7,6 & 7,8 & 8,1 & 8,0 & 8,3 & 9 & 8,6 \\
\hline (c) maggioritari & 3,7 & 5,1 & 3,9 & 3,8 & 4,9 & 4,0 & 3,7 & 4,7 & 3,9 & 3,1 & 4,2 & 3,3 & 3,6 & 4,6 & 3,8 \\
\hline
\end{tabular}

I: tornata elettorale del 6 e del 20 giugno 1993.

II: tornata elettorale del 21 novembre e del 5 dicembre 1993. 
La concomitanza dell'adozione della nuova legge elettorale col processo di destrutturazione partitica rende assai problematico parlare, al singolare, di atteggiamento dei partiti tradizionali. Una condizione necessaria al prodursi di atteggiamenti di resistenza o di adattamento al cambiamento delle regole - ovvero l'esistenza di partiti sufficientemente forti e coesi da essere in grado di definire una propria univoca e coerente strategia competitiva - non è infatti più certa come prima. Su questo terreno, del resto, una stessa evidenza empirica può dipendere da condizioni affatto diverse e alludere a fenomeni distinti. La scomparsa dalla contesa di liste partitiche con contrassegni ufficiali, ad esempio, può indicare $(a)$ un'ormai avanzata disarticolazione strutturale del partito in questione, oppure $(b)$ una scelta di adattamento alle nuove condizioni competitive (formazione di cartelli a sostegno di candidature del sindaco e di liste di schieramento), $\mathrm{o}$, ancora, $(c)$ una scelta di resistenza alle nuove condizioni competitive (maquillage del simbolo e della denominazione o operazioni anfibie di altro tipo). Ma non è soltanto l'assenza di liste partitiche a costituire un indicatore ambiguo, bensì la loro stessa presenza, che potrebbe denotare sia un'effettiva renitenza alla logica (parzialmente) aggregativa del nuovo sistema elettorale sia lo scarso potenziale aggregativo del partito in questione, nella misu$\mathrm{ra}$ in cui il gioco delle alleanze dipende non solo dalla propria volontà $\mathrm{ma}$ anche dalla volontà e dalle percezioni altrui.

Con queste avvertenze si è ricostruita la presenza delle liste partitiche con contrassegno ufficiale e la presenza di candidature monopartitiche alla carica di sindaco (tabb. 5 e 6$)^{20}$. Il primo fenomeno che se ne ricava - lo si può leggere nelle ultime tre linee delle due tabelle - è la tendenziale departitizzazione dell'offerta. La presenza di liste partitiche con contrassegno ufficiale è pari infatti alla metà delle presenze teoricamente possibili a giugno e a meno dei due quinti a novembre-dicembre (per le can-

${ }^{20}$ Per la costruzione delle tabelle di questa come delle successive sezioni si è fatto uso di una pluralità di fonti, la consultazione incrociata delle quali si è resa necessaria soprattutto per pervenire all'identificazione delle liste. Si è fatto uso, in particolare, degli elenchi ufficiale delle liste e candidati ammessi, dei tabulati sull'(ufficiosa) identificazione politica delle liste, degli elenchi dei nominativi (e dell'appartenenza politico-partitica) dei sindaci in carica, di informazioni fornite dagli stessi attori partitici (in particolare PDS, Alleanza democratica, Popolari per la riforma, Unione di centro). Ove non diversamente indicato, le tabelle che seguono sono il risultato di elaborazioni proprie condotte su questi e su altri dati forniti dal Servizio elettorale del Ministero degli Interni. 
ТАв. 5. Presenza di liste di partito (con simbolo ufficiale) e di candidature alla carica di sindaco a sostegno monopartitico alle elezioni comunali del giugno 1993 (valori percentuali calcolati sui 112 comuni con oltre 15.000 abitanti andati al voto)

\begin{tabular}{|c|c|c|c|c|c|c|c|c|c|c|}
\hline & \multicolumn{2}{|c|}{ Nord } & \multicolumn{2}{|c|}{ Centro } & \multicolumn{2}{|c|}{ Sud } & \multicolumn{2}{|r|}{ Isole } & \multicolumn{2}{|r|}{ Italia } \\
\hline & \multicolumn{2}{|c|}{ liste candidature } & \multirow{2}{*}{\multicolumn{2}{|c|}{$\begin{array}{l}\text { liste candidature } \\
\%\end{array}$}} & \multicolumn{2}{|c|}{ liste candidature } & \multicolumn{2}{|c|}{ liste candidature } & \multicolumn{2}{|c|}{ liste candidature } \\
\hline & $\%$ & $\%$ & & & $\%$ & $\%$ & $\%$ & $\%$ & $\%$ & \\
\hline \multicolumn{11}{|l|}{ DC } \\
\hline (a) & 62.5 & 25.0 & 100.0 & 75.0 & - & - & 100.0 & 100.0 & 78.6 & 50.0 \\
\hline (b) & 94.4 & 88.9 & 95.7 & 78.3 & 92.7 & 78.0 & 93.7 & 62.5 & 93.9 & 77.6 \\
\hline (a) $+(b)$ & 84.6 & 69.2 & 96.2 & 77.8 & 92.7 & 78.0 & 94.4 & 66.7 & 92.0 & 74.1 \\
\hline \multicolumn{11}{|l|}{ PDS } \\
\hline (a) & 75.0 & 25.0 & 75.0 & 25.0 & - & - & - & - & 64.3 & 28.6 \\
\hline (b) & 55.5 & 33.3 & 87.0 & 30.4 & 53.7 & 24.4 & 68.7 & 31.2 & 53.1 & 28.6 \\
\hline (a) $+($ b) & 61.5 & 30.8 & 85.2 & 33.3 & 53.7 & 24.4 & 61.1 & 27.8 & 54.5 & 28.6 \\
\hline \multicolumn{11}{|l|}{$\mathrm{RC}$} \\
\hline (a) & 100.0 & 50.0 & 100.0 & 100.0 & - & - & 50.0 & - & 92.9 & 57.1 \\
\hline (b) & 83.3 & 50.0 & 73.9 & 43.5 & 70.7 & 43.9 & 93.7 & 50.0 & 77.6 & 45.9 \\
\hline (a) + (b) & 88.5 & 50.0 & 77.8 & 51.9 & 70.7 & 43.9 & 84.2 & 44.4 & 79.5 & 47.3 \\
\hline \multicolumn{11}{|l|}{ PSI } \\
\hline (a) & 12.5 & 12.5 & 25.0 & 25.0 & - & - & - & - & 14.3 & 14.3 \\
\hline (b) & 44.4 & 38.9 & 47.8 & 21.7 & 41.5 & 24.4 & 43.7 & 12.5 & 43.9 & 24.5 \\
\hline (a) + (b) & 34.6 & 30.8 & 44.4 & 22.2 & 41.5 & 24.4 & 38.9 & 11.1 & 40.2 & 23.2 \\
\hline
\end{tabular}

(a): comuni capoluogo.

(b): comuni non capoluogo. 


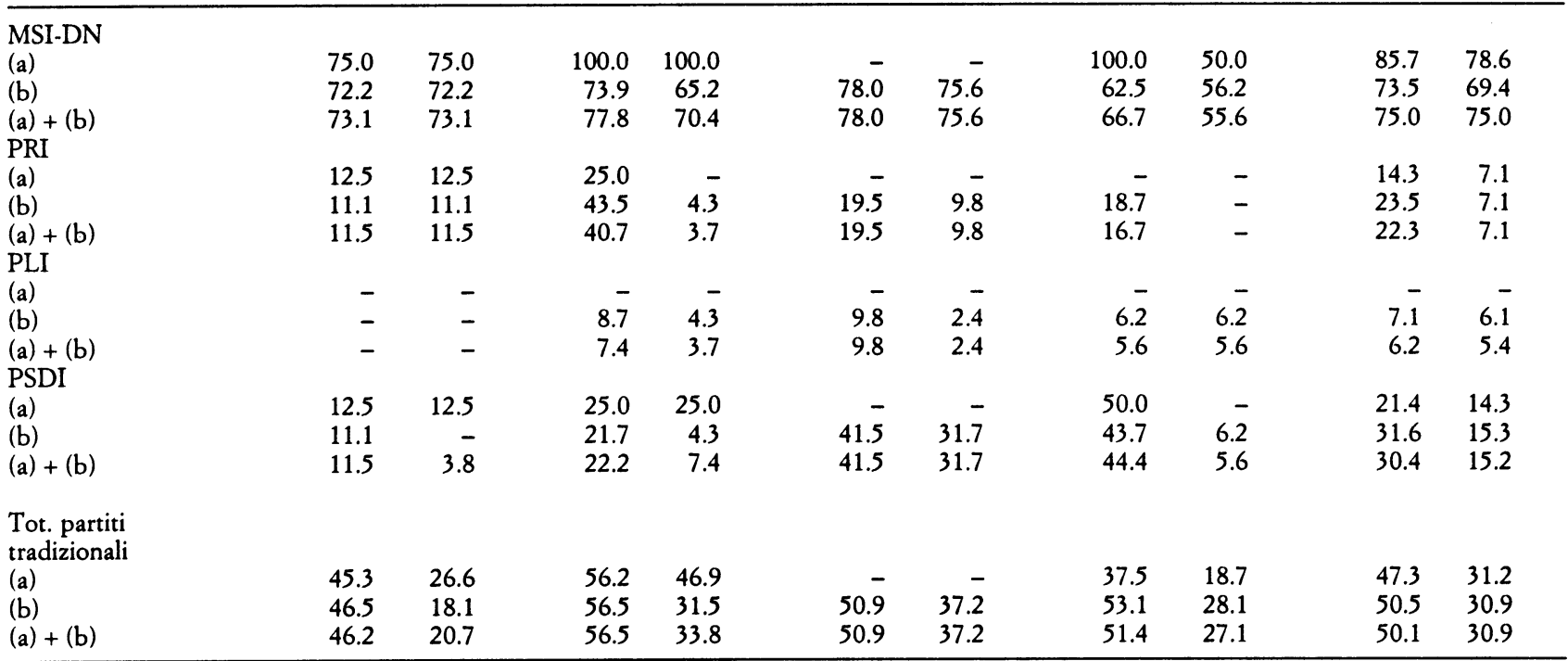

(a): comuni capoluogo.

(b): comuni non capoluogo. 
didature a sostegno monopartitico i valori sono invece, rispettivamente, $30,9 \%$ e $17,6 \%$ ). Rispetto alle ultime elezioni svoltesi con la vecchia legge elettorale (e prima del manifestarsi del processo di destrutturazione) la presenza di liste partitiche con contrassegno ufficiale registra un calo di oltre 40 punti. Fra la tornata estiva e quella autunnale, inoltre, la presenza di liste partitiche con contrassegno ufficiale si riduce dal $62 \%$ al $45 \%$ del totale delle liste in corsa, a fronte - lo si è visto nella tab. 4 - di una crescita del numero medio di liste presenti.

Dal punto di vista dei singoli partiti, le tabb. 5 e 6 pongono in rilievo tre fenomeni principali: (a) differenze significative nel grado di presenza con proprie liste ufficiali fra un partito e l'altro; (b) differenze altrettanto significative in termini di scarto fra presenza di liste e presenza di candidature (monopartitiche); (c) generalizzato declino della presenza sia delle liste partitiche con contrassegno ufficiale sia delle candidature monopartitiche nel passaggio elettorale autunnale, pur se con intensità diversa da un partito all'altro.

Tre partiti esibiscono, in giugno, una presenza uti singuli di gran lunga maggiore rispetto agli altri. Si tratta di Rifondazione comunista, MSI-DN e DC. Tale presenza registra differenze associate alla grandezza demografica dei comuni, e, quindi, a un diverso tipo di radicamento territoriale (maggiormente concentrato nei capoluoghi per RC e MSI, nei centri minori per la DC), e corrisponde a ragioni distinte. Nell'arena consiliare, correre in proprio e coi colori ufficiali della scuderia rappresentava per $i$ due partiti estremi una scelta in buona parte obbligata, connessa alla loro stessa collocazione spaziale, alla conseguente difficoltà (più per il MSI-DN che per RC) di trovare interlocutori, alla necessità di restare «visibili». Nel caso della DC tale opzione configurava invece una scelta adottata per lo più per inerzia, in una situazione di crisi propria e dei propri potenziali interlocutori (i tradizionali alleati di governo), e denota soprattutto incapacità di adattamento alle nuove regole e, semmai, un tentativo di risposta alle minacce intestine, provenienti sia dai Popolari per la riforma di Segni sia da situazioni di malessere locale sfociate a volte nella costituzione di liste dissidenti di area. I dati relativi all'arena esecutiva confermano questa diagnosi. Si può infatti ipotizzare che lo scarto fra presenza di liste ufficiali di partito e presenza di candidature monopartitiche risulti tanto minore quanto maggiore sia l'isolamento competitivo (scelto o imposto) del partito cui esso si riferisce e quanto mi- 
TAB. 6. Presenza di liste di partito (con simbolo ufficiale) e di candidature alla carica di sindaco a sostegno monopartitico alle elezioni comunali del novembre-dicembre 1993 (valori percentuali calcolati sui 99 comuni con oltre 15.000 abitanti andati al voto)

\begin{tabular}{|c|c|c|c|c|c|c|c|c|c|c|}
\hline & \multicolumn{2}{|c|}{ Nord } & \multicolumn{2}{|c|}{ Centro } & \multicolumn{2}{|c|}{ Sud } & \multicolumn{2}{|c|}{ Isole } & \multicolumn{2}{|c|}{ Italia } \\
\hline & \multicolumn{2}{|c|}{ liste candidature } & \multicolumn{2}{|c|}{ liste candidature } & \multicolumn{2}{|c|}{ liste candidature } & \multicolumn{2}{|c|}{ liste candidature } & \multicolumn{2}{|c|}{ liste candidature } \\
\hline & $\%$ & $\%$ & $\%$ & $\%$ & $\%$ & $\%$ & $\%$ & $\%$ & $\%$ & $\%$ \\
\hline \multicolumn{11}{|l|}{ DC } \\
\hline (a) & 50.0 & - & 100.0 & - & 50.0 & 12.5 & 100.0 & - & 63.2 & 5.3 \\
\hline (b) & 74.2 & 32.2 & 85.7 & - & 66.7 & 38.1 & 81.0 & 57.1 & 75.0 & 37.5 \\
\hline (a) $+(b)$ & 70.3 & 27.0 & 90.0 & - & 62.1 & 31.0 & 82.6 & 52.2 & 72.7 & 31.3 \\
\hline \multicolumn{11}{|l|}{ PDS } \\
\hline $\begin{array}{l}\text { (a) } \\
\text { (b) }\end{array}$ & $\begin{array}{l}83.3 \\
61.3\end{array}$ & $6 \overline{5}$ & $\begin{array}{r}100.0 \\
857\end{array}$ & $14 \overline{3}$ & 50.0 & $\overline{-}$ & - & - & 63.2 & $15 \overline{0}$ \\
\hline$(a)+(b)$ & 64.9 & 5.4 & 90.0 & 14.3 & $\begin{array}{l}41.6 \\
483\end{array}$ & 28.6 & 61.9 & 14.3 & 60.0 & $\begin{array}{l}15.0 \\
121\end{array}$ \\
\hline \multicolumn{11}{|l|}{ RC } \\
\hline (a) & 100.0 & 83.3 & 100.0 & 33.3 & 87.5 & 25.0 & 100.0 & - & 94.7 & 42.1 \\
\hline (b) & 93.5 & 61.3 & 100.0 & 42.9 & 47.6 & 33.3 & 42.9 & - & 68.7 & 36.2 \\
\hline (a) $+(b)$ & 94.6 & 64.9 & 100.0 & 40.0 & 58.6 & 31.0 & 47.8 & - & 73.7 & 37.4 \\
\hline \multicolumn{11}{|l|}{ PSI } \\
\hline (a) & - & - & - & - & 12.5 & - & - & - & 5.3 & - \\
\hline (b) & 9.7 & 3.2 & 42.9 & 14.3 & 19.0 & 14.3 & 9.5 & 4.8 & 15.0 & 7.5 \\
\hline (a) $+(b)$ & 8.1 & 2.7 & 30.0 & 10.0 & 17.2 & 10.3 & 8.7 & 4.3 & 13.1 & 6.1 \\
\hline
\end{tabular}

(a): comuni capoluogo.

(b): comuni non capoluogo. 


\begin{tabular}{|c|c|c|c|c|c|c|c|c|c|c|}
\hline $\begin{array}{l}\text { MSI-DN } \\
\text { (a) }\end{array}$ & 83.3 & 66.7 & 33.3 & - & 62.5 & 62.5 & 50.0 & - & 63.2 & 47.4 \\
\hline (b) & 48.4 & 45.2 & 71.4 & 42.9 & 81.0 & 71.4 & 61.9 & 33.3 & 62.5 & 48.7 \\
\hline (a) + (b) & 54.1 & 48.6 & 60.0 & 30.0 & 75.9 & 69.0 & 60.9 & 30.4 & 62.6 & 48.5 \\
\hline \multicolumn{11}{|l|}{ PRI } \\
\hline $\begin{array}{l}\text { (a) } \\
\text { (b) }\end{array}$ & - & - & $\begin{array}{l}33.3 \\
57.1\end{array}$ & $\begin{array}{r}33.3 \\
-\end{array}$ & $9 . \overline{5}$ & 9.5 & 14.3 & - & 11.2 & $\begin{array}{l}3.5 \\
2.5\end{array}$ \\
\hline (a) + (b) & - & - & 50.0 & 30.0 & 6.9 & 6.9 & 13.0 & - & 10.1 & 3.0 \\
\hline \multicolumn{11}{|l|}{ PLI } \\
\hline (a) & - & - & - & - & 12.5 & - & - & - & 5.3 & - \\
\hline (b) & 3.2 & 3.2 & - & - & - & - & - & - & 1.2 & 1.2 \\
\hline (a) + (b) & 2.7 & 2.7 & - & - & 3.4 & - & - & - & 2.0 & 1.0 \\
\hline \multicolumn{11}{|l|}{ PSDI } \\
\hline (a) & - & - & 33.3 & - & 37.5 & - & 50.0 & - & 26.3 & - \\
\hline (b) & 3.2 & - & 14.3 & 14.3 & 4.8 & 4.8 & 23.8 & - & 10.0 & 1.2 \\
\hline (a) + (b) & 2.7 & - & 20.0 & 20.0 & 13.8 & 3.4 & 26.1 & - & 13.1 & 1.0 \\
\hline \multicolumn{11}{|l|}{ Tot. partiti } \\
\hline (a) & 39.6 & 18.7 & 50.0 & 8.3 & 39.1 & 10.9 & 37.5 & - & 40.8 & 11.8 \\
\hline (b) & 36.7 & 20.6 & 57.1 & 14.3 & 34.5 & 23.2 & 36.9 & 13.7 & 38.0 & 18.9 \\
\hline (a) $+(b)$ & 37.2 & 20.3 & 55.0 & 12.5 & 35.8 & 19.8 & 37.0 & 12.5 & 38.5 & 17.6 \\
\hline
\end{tabular}

(a): comuni capoluogo.

(b): comuni non capoluogo 
nore, di conseguenza, sia il suo adattamento alle nuove condizioni competitive. Rispetto agli altri partiti, Rifondazione comunista, MSI-DN e DC esibiscono infatti anche nell'arena esecutiva una presenza monopartitica assai maggiore e, soprattutto, assai più prossima alla loro presenza di lista ${ }^{21}$.

Nella tornata autunnale, RC, MSI-DN e DC mantengono il loro primato in entrambe le arene, ma riducono in maniera significativa l'incidenza della loro presenza (tab. 6). Questo riorientamento strategico segnala, almeno in parte, un processo di apprendimento intervenuto fra un passaggio elettorale e l'altro. Nel caso del MSI-DN si riscontra soprattutto un maggiore scostamento fra le due arene, in particolare nelle zone di maggior insediamento elettorale (i comuni del Centro e del Sud), per la presenza di un maggior numero di candidature di area («tricolori», di destra, di Alleanza nazionale) sostenute da coalizioni composte dal MSI e da liste civiche a volte costituite ad boc. Rifondazione comunista, a sua volta, ridimensiona la propria presenza autonoma nell'arena esecutiva, dopo che in giugno l'elettorato aveva mostrato di apprezzare più le liste che le candidature neo-comuniste, orientando il proprio voto nell'arena esecutiva verso candidati di sinistra con maggiori chances di successo. Nel caso della DC, infine, alla caduta verticale della presenza di candidature solo democristiane corrisponde una ridimensionata presenza nell'arena rappresentativa. Si tratta di effetti connessi, da un lato, all'adozione, sul fronte delle liste, di un atteggiamento mimetico connesso in alcuni casi anche alla faticosa trasformazione della DC in Partito popolare, e, dall'altro, al frequente ricorso ad accordi di coalizione con i partiti laici a sostegno di comuni candidature di centro.

Le tabb. 5 e 6 registrano anche la diaspora dei partiti dell'area intermedia e il suo progredire dal passaggio elettorale estivo a quello autunnale. La presenza di liste ufficiali e di candidature monopartitiche è infatti nel caso dei partiti laici e socialisti assai ridotta e in declino. Questa assenza è diretta conseguenza della disarticolazione organizzativa di tali partiti e segnala, a volte, la loro inca-

21 Stando ai dati della tab. 6 e all'ipotesi appena presentata, Rifondazione comunista godrebbe rispetto al MSI-DN di un minor isolamento competitivo e infatti, soprattutto nei centri minori, i neo-comunisti sostengono candidati di sinistra, nel quadro di coalizioni incentrate sul PDS o di cartelli più ristretti assieme a Rete e Verdi (si veda, più avanti, la tab. 8). Il MSI, dal canto suo, presenta uno scarto fra le due arene maggiore nel Sud, e quindi nelle sue zone di maggior forza elettorale, dove può quindi contare su uno spazio di manovra più ampio che altrove. 
pacità di raccogliere le firme necessarie alla presentazione delle liste e delle candidature, di trovare i candidati, di trattenere esponenti e gruppi locali «in fuga» (è il caso, ad esempio, del PSI, soprattutto in alcuni comuni del Nord). Altre volte l'assenza è invece dovuta a dinamiche interne di natura centrifuga che hanno finito per spaccare tali partiti, calamitandoli in schieramenti e alleanze contrapposte (in liste e a sostegno di candidature centriste al Sud; nelle aggregazioni «di progresso» formatesi attorno al PDS al Centro e spesso anche al Nord) com'è accaduto al PRI.

Una strategia competitiva diversa dalle precedenti l'ha adottata il PDS, presente in quasi la metà dei comuni con proprie liste, ma con assai minore frequenza (ovvero poco più di un quarto dei comuni in giugno, nessun capoluogo di provincia $\mathrm{e}$ il $15 \%$ dei comuni non capoluogo in novembre-dicembre) con proprie candidature. L'evidente scostamento fra presenza ufficiale di lista e presenza di candidature monopartitiche corrisponde, nel caso del PDS, ad un pronto adattamento alle nuove regole e alla capacità di proporsi come fulcro di numerosi e variegati cartelli elettorali. Il partito di Occhetto e D'Alema ha messo a frutto, in tal modo, un potenziale di coalizione e uno spazio di manovra accresciutisi grazie a una tenuta politico-organizzativa relativa ma, in un quadro di progressiva destrutturazione strutturale altrui, comparativamente considerevole.

La relativa «latitanza» dei partiti tradizionali ha determinato una differenziazione dell'offerta - con o senza parallela frammentazione - in ragione di molteplici fattori (dalle diverse tradizioni partitiche locali al differenziato impatto della «sfida giudiziaria» e delle sue conseguenze politiche). In sostituzione delle liste partitiche tradizionali hanno partecipato alla contesa liste di area (liste partitiche camuffate, liste partitiche dissidenti, liste partitiche «rinnovate» prive del simbolo ufficiale, liste di convergenza locale), liste miste (di centro, di sinistra, di destra), etichette a sfondo civico-municipalistico ${ }^{22}$. Un ulteriore elemento di novità era costituito dalla presenza di liste di formazioni politiche nuove.

Sulla base degli stessi criteri utilizzati nelle tabb. 5 e 6, la tab. 7 ne ricostruisce la diffusione. A giugno tali formazioni

${ }^{22}$ Si tratta di liste dal profilo politico non sempre facilmente identificabile. Sulla base delle fonti citate nella nota precedente, si è tuttavia proceduto a classificare singole liste di questo tipo effettivamente rilevanti, ovvero sostenitrici, da sole o in alleanza con altre, di candidati-sindaco vincenti o ammessi al ballottaggio. 
TAB. 7. Presenza delle liste di nuove formazioni e di loro candidature alla carica di sindaco (valori percentuali calcolati sui $112+99$ comuni con oltre 15.000 abitanti andati al voto nel giugno e nel novembre-dicembre 1993)

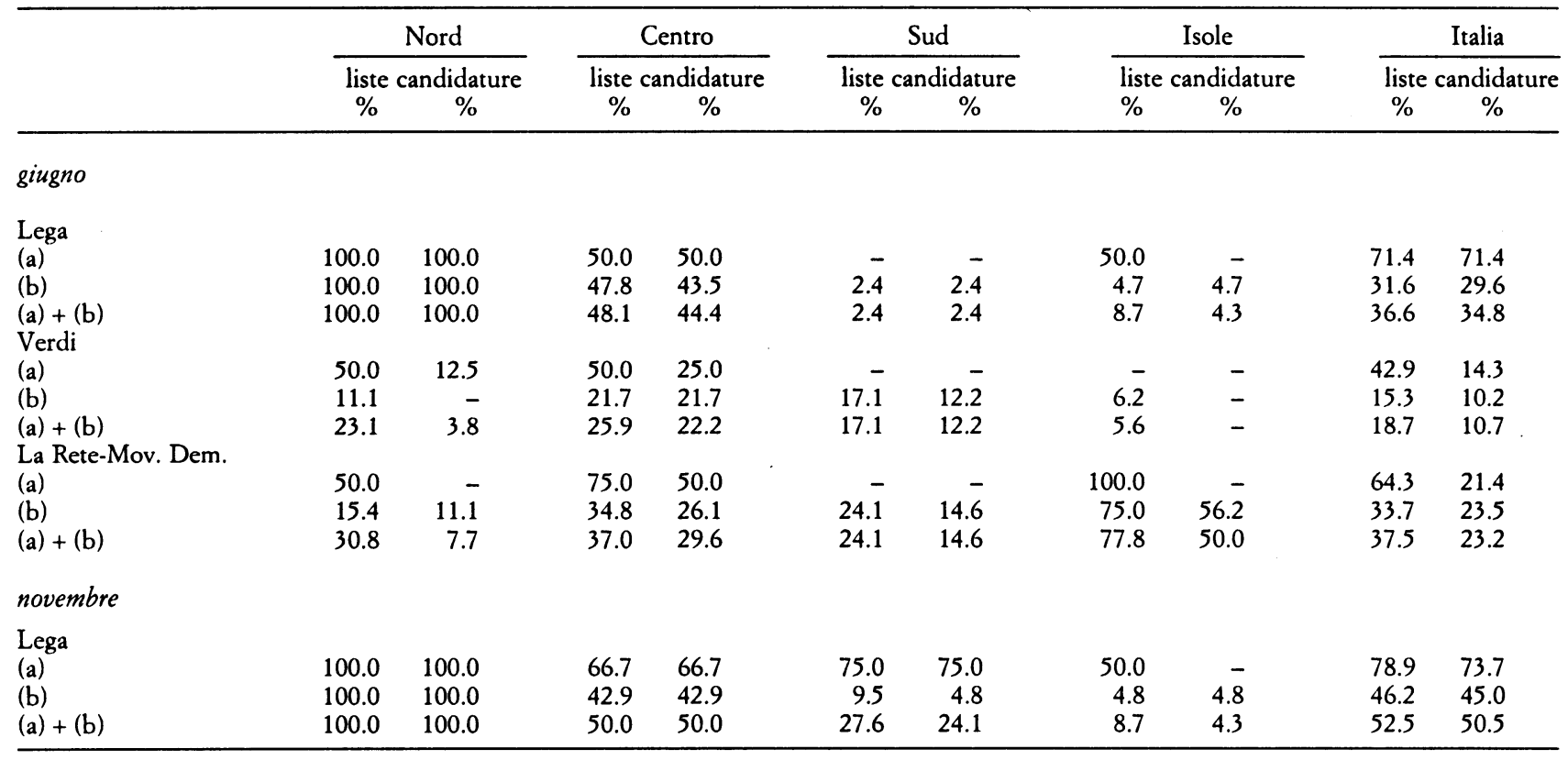

(a): comuni capolugo.

(b): comuni non capoluogo. 


\begin{tabular}{|c|c|c|c|c|c|c|c|c|c|c|}
\hline $\begin{array}{l}\text { Verdi } \\
\text { (a) }\end{array}$ & 66.7 & - & 66.7 & 33.3 & 50.0 & - & - & - & 52.6 & 5.3 \\
\hline (b) & 48.4 & 16.1 & 71.4 & 14.3 & 23.8 & 14.3 & - & - & 31.2 & 11.2 \\
\hline (a) $+(b)$ & 51.4 & 13.5 & 70.0 & 20.0 & 31.0 & 10.3 & - & - & 35.4 & 10.1 \\
\hline $\begin{array}{l}\text { La Rete-Mov.Dem. } \\
\text { (a) }\end{array}$ & 50.0 & 16.7 & 66.7 & 33.3 & 50.0 & - & 100.0 & 50.0 & 57.9 & 15.8 \\
\hline (b) & 22.6 & 3.2 & 42.9 & - & 9.5 & 4.8 & 61.9 & 33.3 & 31.2 & 11.2 \\
\hline (a) $+(b)$ & 27.0 & 5.4 & 50.0 & 10.0 & 20.7 & 3.4 & 65.2 & 34.8 & 36.4 & 12.1 \\
\hline Alleanza-Patto & & & & & & & & & & \\
\hline (a) & 66.7 & - & 33.3 & - & 12.5 & 12.5 & 50.0 & - & 36.8 & 5.3 \\
\hline (b) & 6.4 & 6.4 & 28.6 & 28.6 & 4.7 & 4.7 & 4.7 & - & 7.5 & 6.2 \\
\hline$(a)+(b)$ & 16.2 & 5.4 & 30.0 & 20.0 & 6.9 & 6.9 & 8.7 & - & 13.1 & 6.1 \\
\hline Alleanza Democratica & & & & & & & & & & \\
\hline (a) & 16.7 & - & 66.7 & - & 25.0 & 12.5 & - & - & 26.3 & 5.3 \\
\hline (b) & 16.1 & 3.2 & 14.3 & - & 4.7 & - & 9.5 & - & 12.5 & 1.2 \\
\hline (a) + (b) & 16.2 & 2.7 & 30.0 & - & 6.9 & 3.4 & 8.7 & - & 15.1 & 2.0 \\
\hline Popolari per la Riforma & & & & & & & & & & \\
\hline (a) & 33.3 & 16.7 & 33.3 & - & 37.5 & 25.0 & - & - & 31.6 & 15.8 \\
\hline (b) & 38.7 & 22.6 & 14.3 & - & 33.3 & 28.6 & 42.9 & 19.0 & 36.2 & 21.2 \\
\hline$(a)+(b)$ & 37.8 & 21.6 & 20.0 & - & 34.5 & 27.6 & 39.1 & 17.4 & 35.3 & 20.2 \\
\hline Unione di Centro & & & & & & & & & & \\
\hline $\begin{array}{l}\text { (a) } \\
\text { (b) }\end{array}$ & 33.3 & 16.7 & 66.7 & - & 25.0 & - & 50.0 & 50.0 & 36.8 & $\begin{array}{r}10.5 \\
12\end{array}$ \\
\hline $\begin{array}{l}\text { (b) } \\
\text { (a) }+(\text { b) }\end{array}$ & 3.2 & 3.2 & - & - & - & - & - & - & 1.2 & 1.2 \\
\hline$(a)+(b)$ & 8.1 & 5.4 & 20.0 & - & 6.9 & - & 4.3 & 4.3 & 8.1 & 3.0 \\
\hline
\end{tabular}

(a): comuni capolugo.

(b): comuni non capoluogo. 
sono nuove soltanto a metà. Lega, Verdi e Rete sono però accomunate da un atteggiamento di contestazione nei confronti dei partiti tradizionali e dall'occupazione della dimensione «antipolitica» dello spazio competitivo (Bardi e Morlino 1994), cresciuta a dismisura nell'ultimo biennio. A novembre-dicembre alle tre precedenti si aggiungono Alleanza democratica e i Popolari per la riforma (a volte assieme nelle liste Alleanza-Patto) e l'Unione di centro. Nessuna di queste formazioni adotta il termine «partito», caduto ormai in disgrazia sotto i duri colpi dell'azione giudiziaria e la cui sfortuna ne segnala il significato ormai derogatorio.

Con la sola eccezione della Lega, la presenza competitiva di queste nuove formazioni è piuttosto diseguale, si concentra in prevalenza nei centri urbani (con la parziale eccezione dei Popolari per la riforma), denota una piena sintonia con le nuove regole. Nell'arena esecutiva, infatti, le nuove formazioni propendono all'appoggio di candidature di coalizione, per lo più di sinistra (nel caso di Verdi, Rete, Alleanza democratica ed anche, pur se non sempre, Popolari per la riforma), altre volte di centro (Unione di centro, ma anche Popolari per la riforma).

In questo panorama, la Lega esibisce una condotta strategica atipica, di totale autarchia competitiva. La Lega presenta infatti ovunque - ovvero in tutti i comuni del Nord, in circa la metà dei comuni del Centro, nei centri capoluogo del Mezzogiorno (spesso, in quest'ultimo caso, con l'etichetta «Lega-Italia federale») - liste e candidature proprie. Evitando qualsiasi forma di accordo e alleanza con altri, la Lega puntava a saggiare la propria vocazione maggioritaria nel nord del paese e la propria autonoma capacità di penetrazione a sud della linea gotica, muovendosi però controcorrente rispetto alla logica del nuovo sistema elettorale.

Il «vuoto» lasciato dai partiti tradizionali è stato colmato, da un altro punto di vista, dai candidati alla carica di sindaco. L'impiego del nuovo sistema elettorale ne ha accresciuto il peso specifico, determinando, com'era prevedibile, una maggiore personalizzazione della campagna elettorale. Il processo di destrutturazione partitica, dal canto suo, ne ha favorito la differenziazione su base territoriale, con conseguenze sulla competizione e sui risultati che richiederebbero un approfondimento a parte. Mentre al Sud, in presenza di un tessuto civico e associativo più gracile e di una più netta frontiera fra partiti di governo (locale) e partiti di opposizione, le candidature (e poi i sin- 
daci) hanno mantenuto per lo più il tradizionale profilo partitico, in molti comuni del Nord, e soprattutto nelle grandi città, sono emerse candidature, spesso vincenti, di estrazione non tanto partitica quanto più direttamente societaria (imprese, professioni, università) ${ }^{23}$.

Un aspetto sempre relativo ai candidati alla carica di sindaco, ma più specificamente connesso all'esame dell'offerta e della geometria delle alleanze e alle modalità della competizione, è la definizione del loro colore politico. I casi contemplati dalle tabb. 5, 6 e 7 non fanno problema, poiché si riferiscono a candidature a carattere monopartitico. Diverso è il caso delle candidature a sostegno multipartitico. La tab. 8 ne presenta una mappa che si articola in sei classi: tre per le candidature appartenenti alla famiglia della sinistra (la sinistra dell'antagonismo e della protesta sociale, la sinistra allargata delle alleanze «di progresso», la sinistra «con-nemici-a-sinistra» delle candidature di area PDS e di sinistra-centro, alcune delle quali - ad esempio quella di Illy a Trieste - si allargano fino a settori democristiani), due per le candidature centriste (di area laico-socialista; di area democristiana o di convergenza fra le due), una per le candidature di destra (le alleanze di area missina, che in pochi casi, fra cui Trieste, si estendono a componenti centriste).

Il principale fenomeno che si ricava dalla tab. 8 è l'accresciuta presenza di candidature sostenute da una coalizione di liste e, quindi, il maturare di un processo di apprendimento fra il passaggio elettorale estivo e quello autunnale. Tale fenomeno si manifesta nell'intero spettro politico. Più contenuto a destra, per le difficoltà incontrate dal MSI-DN nel varare candidature di Alleanza nazionale, esso è particolarmente accentuato a sinistra e al centro, specularmente alla minor presenza di candidature monopartitiche pidiessine, neo-comuniste e democristiane (tabb. 5 e 6). A sinistra crescono sia le candidature sostenute da coalizioni «di progresso», senza frontiere a sinistra, sia le candi-

${ }^{23}$ È il caso di Castellani a Torino, di Sansa a Genova, di Cacciari a Venezia, di Illy a Trieste, di Jannaccone Pazzi a Pavia (cui corrisponde invece l'elezione del verde Rutelli a Roma, del pidiessino Bassolino a Napoli, del retino ed ex sindaco democristiano Orlando a Palermo, dell'ex segretario socialista Mancini a Cosenza). Oltre che a una più ricca e articolata trama societaria, le candidature della società civile corrispondono a situazioni in cui, per tutti gli anni Ottanta e oltre, più frequente è stato l'alternarsi delle maggioranze di governo locale e sostanzialmente corresponsabili della conduzione della politica municipale sono stati i principali partiti. 
TAB. 8. Connotazione politica e diffusione delle alleanze a sostegno delle candidature alla carica di sindaco (valori percentuali calcolati sui $112+99$ comuni con oltre 15.000 abitanti andati al voto nel giugno e nel novembre-dicembre 1993)

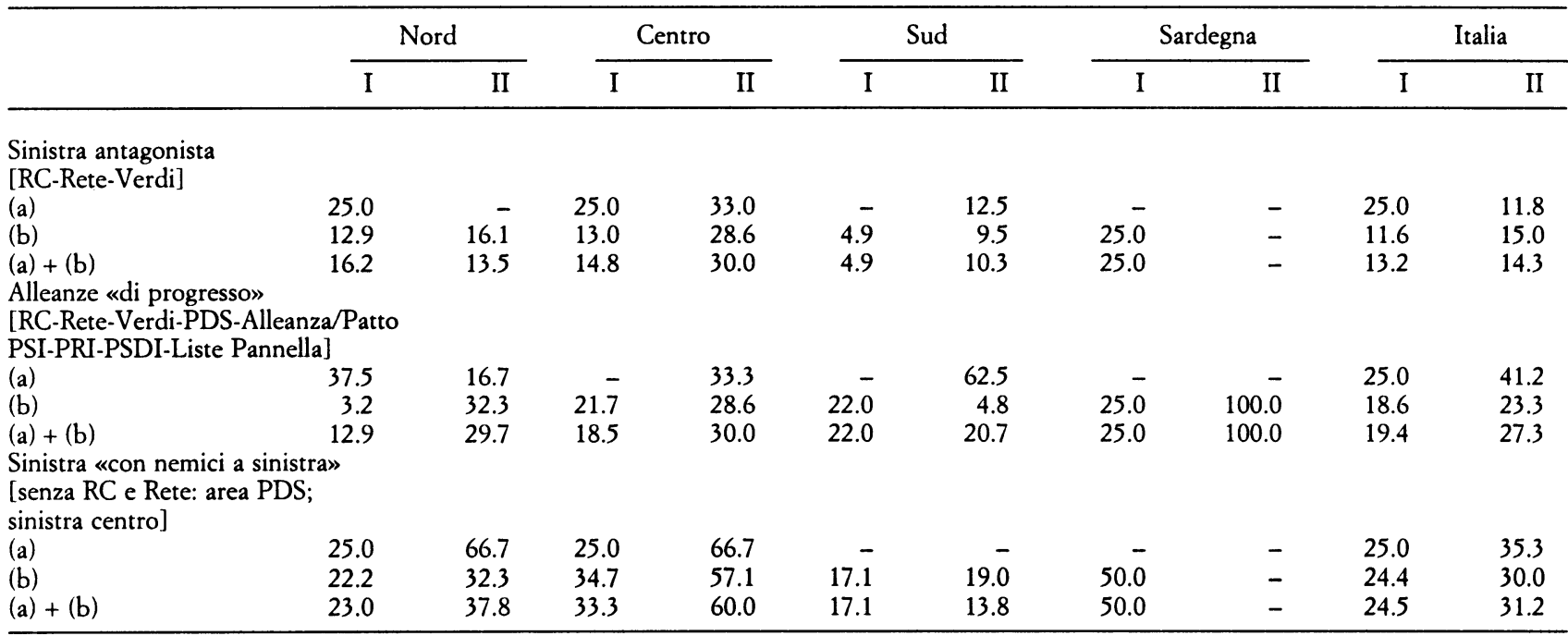

I: tornata elettorale del 6 e del 20 giugno 1993

II: tornata elettorale del 21 novembre e del 5 dicembre 1993. 


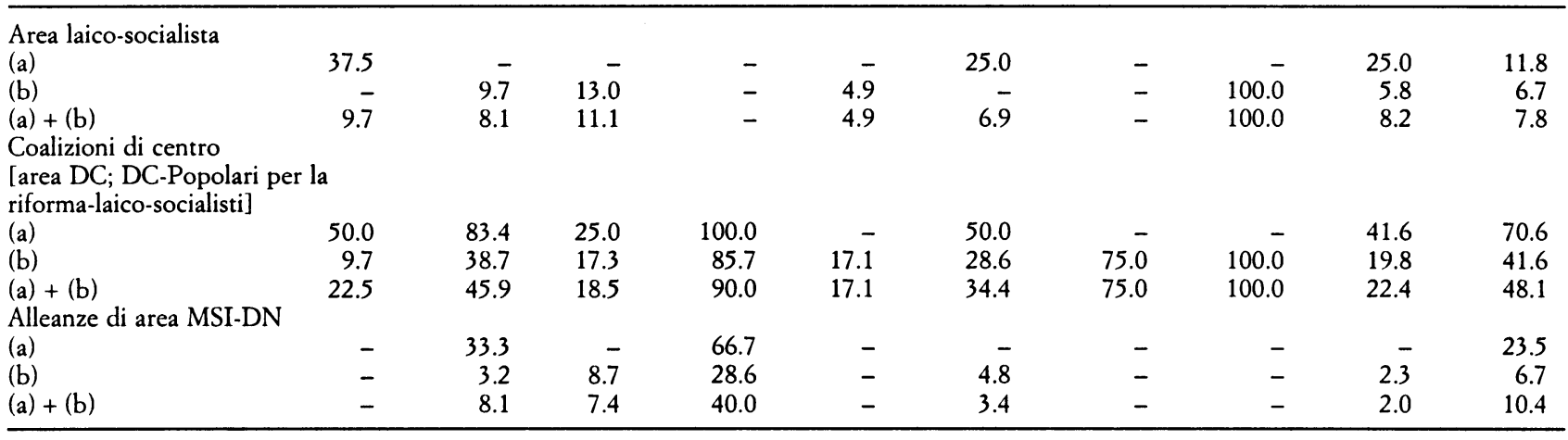

I: tornata elettorale del 6 e del 20 giugno 1993.

II: tornata elettorale del 21 novembre e del 5 dicembre 1993. 
dature di sinistra-centro, con variazioni territoriali dovute alla molteplicità delle specifiche condizioni locali. La maggior coalescenza dell'area di centro si realizza prevalentemente attraverso la convergenza fra DC e partiti di area laica e socialista, senza escludere in alcuni casi i Popolari di Segni.

\section{Due arene a confronto}

Così definite le strategie competitive di partiti e candidati, le prossime sezioni sono destinate alle risposte degli elettori, posti di fronte, al tempo stesso, a nuove regole di selezione dei vertici del governo municipale e di composizione dei consigli e a un'offerta assai diversa rispetto al passato. Questo paragrafo prende in esame $i$ risultati alla luce della duplicazione delle arene elettorali. Il paragrafo seguente si sofferma invece sul turno di ballottaggio.

Una prima serie di considerazioni scaturisce dai dati relativi alla partecipazione elettorale riportati nelle tabb. 9 e 10 . In un quadro di astensionismo crescente (di circa sette punti) ${ }^{24}$, si segnala ad esempio, come fenomeno inatteso, il ridursi della tradizionale forbice fra Nord e Sud, soprattutto nella tornata estiva. A tale fenomeno corrispondono andamenti ancora più atipici, legati all'impiego di modalità differenziate di espressione del voto da parte degli elettori. Succede così che nei comuni del Sud a giugno e nei comuni siciliani a novembre si riscontrino le percentuali più alte di voti validi di lista. Se si considerano i voti validi per l'arena esecutiva l'andamento territoriale assume distribuzioni più «ortodosse», a causa del diseguale impiego del voto al solo sindaco.

L'adozione di questa opzione di voto (e la rinuncia ad esprimere un voto per il consiglio e quindi una preferenza per una lista più o meno partitica) interessa una quota non trascurabile di elettori, che dalla tornata estiva a quella autunnale cresce dall' $11.2 \%$ al $15.4 \%$ dei votanti. In questo tipo di scelta convergono motivazioni diverse, dalla personalizzazione indotta

${ }^{24}$ Nell'indisponibilità del dato sulla partecipazione al voto nelle ultime elezioni svoltesi col vecchio sistema elettorale nei 211 comuni con oltre 15.000 abitanti andati al voto fra giugno e novembre-dicembre, si è assunto come termine di confronto il livello di affluenza alle urne delle elezioni comunali del 1990, pari, su scala nazionale, all' $86.3 \%$ degli elettori iscritti. 
dall'investitura diretta del sindaco, all'«arretramento» partitico di cui si è detto, al diffuso sentimento di ostilità cresciuto nei confronti dei partiti nei mesi che hanno preceduto il voto. L'orientamento a votare unicamente per il sindaco è strettamente associato alla dimensione demografica dei comuni ed è più evidente nei grandi centri urbani e nei comuni capoluogo, dove più intenso appare il mix di motivazioni che ne spiegano l'impiego. Non manca tuttavia un'influenza di tipo territoriale, legata forse alla diversa cifra delle candidature che, come si ricordava poco sopra, si dà nelle diverse parti del paese, e alla maggior deferenza rispetto ai partiti che continua a caratterizzare i comuni del Mezzogiorno.

Una conferma della selettività dei comportamenti dell'elettorato - e della sua capacità di adattamento alla logica del nuovo, complesso sistema elettorale - si ricava da un secondo insieme di dati, anch'esso di tipo aggregato e «lontano» dai risultati per singole liste e candidati. Si tratta del grado di concentrazione del voto nelle due arene elettorali, da cui emergono non tanto indicazioni (per quanto indirette e da precisare) sull'impiego del «voto diviso», quanto circostanziati elementi sull'effettiva estensione dello spazio competitivo.

Il minor «affollamento» dell'arena esecutiva rispetto all'arena rappresentativa (tab. 4) e la diversa logica dei rispettivi meccanismi elettorali rendono la concentrazione del voto per la scelta del sindaco, com'era prevedibile, maggiore di quella per l'elezione del consiglio. La forza manipolativa del doppio turno «chiuso» finisce col ridurre lo spazio competitivo dell'arena esecutiva ai due-tre candidati ritenuti in grado di ottenere un piazzamento di testa e quindi l'accesso al ballottaggio ${ }^{25}$. Nella meno manipolativa arena rappresentativa - fondata pur sempre, al di là della possibile attribuzione del premio maggioritario alle forze collegate al candidato-sindaco eletto al secondo turno, sul criterio proporzionale - lo spazio competitivo resta più esteso.

La tab. 11 consente di osservare il quantum di tali differenze e di apprezzare soprattutto l'andamento diacronico del fenomeno, che segnala una lieve crescita della dispersione del voto

${ }^{25} \grave{E}$ a questo riguardo che si pone la questione del ruolo dei sondaggi, strumento che fornisce all'elettore razionale che non voglia sprecare il proprio voto informazioni assai utili, ma al tempo stesso strumento di (indebita e assai poco democratica) selezione non tanto del candidato vincente quanto dei candidati che possono effettivamente correre per vincere. 
TAB. 9. Partecipazione elettorale e non voto; modalità di voto (6 giugno 1993) (percentuali su elettori iscritti)

\begin{tabular}{|c|c|c|c|c|c|c|c|}
\hline & \multirow{2}{*}{$\begin{array}{c}\text { Nord } \\
\%\end{array}$} & \multirow{2}{*}{$\begin{array}{c}\text { Centro } \\
\text { \% }\end{array}$} & \multirow{2}{*}{$\begin{array}{c}\text { Sud } \\
\%\end{array}$} & \multicolumn{2}{|c|}{ Isole } & \multicolumn{2}{|c|}{ Italia } \\
\hline & & & & $\begin{array}{c}\text { Sardegna } \\
\%\end{array}$ & $\begin{array}{c}\text { Sicilia } \\
\%\end{array}$ & $\begin{array}{c}\text { Sicilia escl. } \\
\%\end{array}$ & $\underset{\%}{\text { Sicilia incl. }}$ \\
\hline comuni metropolitani & (2) & & & & & (2) & (2) \\
\hline (Elettori) & $(2.024 .748)$ & & & & & $(2.024 .748)$ & $(2.024 .748)$ \\
\hline Votanti & 77.7 & & & & & 77.7 & 77.7 \\
\hline Non voto & 26.3 & & & & & 26.3 & 26.3 \\
\hline Voti validi (sindaco) & 73.7 & & & & & 73.7 & 73.7 \\
\hline Voti validi (lista) & 58.6 & & & & & 58.6 & 58.6 \\
\hline Voto per il solo sindaco & 15.1 & & & & & 15.1 & \\
\hline comuni capoluogo: & (8) & (4) & & & (2) & $(12)$ & (14) \\
\hline (Elettori) & $(2.414 .671)$ & $(291.801)$ & & & $(327.533)$ & $(2.706 .472)$ & $(3.034 .005)$ \\
\hline Votanti & 79.0 & 83.9 & & & 73.3 & 79.6 & 78.9 \\
\hline Non voto & 25.3 & 21.8 & & & 33.0 & 24.9 & 25.8 \\
\hline Voti validi (sindaco) & 74.7 & 78.2 & & & 67.0 & 75.1 & 74.2 \\
\hline Voti validi (lista) & 72.8 & 71.2 & & & 65.9 & 62.0 & 62.5 \\
\hline Voto per il solo sindaco & & & & & & & \\
\hline
\end{tabular}




\begin{tabular}{|c|c|c|c|c|c|c|c|}
\hline comuni non capoluogo: & (18) (23) & $(41)$ & (4) & $(12)$ & $(86)$ & (98) & \\
\hline (Elettori) & $(395.091)$ & $(530.974)$ & $(1.052 .641)$ & $(109.017)$ & $(253.056)$ & \multicolumn{2}{|c|}{$(2.087 .723)(2.340 .779)$} \\
\hline Votanti & 85.0 & 82.9 & 79.0 & 75.9 & 73.8 & 81.0 & 80.2 \\
\hline Non voto & 20.4 & 23.3 & 25.8 & 33.1 & 33.0 & 24.6 & 25.4 \\
\hline Voti validi (sindaco) & 79.6 & 76.7 & 74.2 & 66.9 & 67.0 & 75.5 & 74.6 \\
\hline Voti validi (lista) & 74.3 & 72.4 & 71.4 & 61.4 & 68.9 & 71.7 & 71.4 \\
\hline Voto per il solo sindaco & 5.3 & 4.3 & 2.8 & 5.5 & - & 3.8 & \\
\hline totale: & $(26)$ & (27) & $(41)$ & (4) & (14) & (98) & $(112)$ \\
\hline (Elettori) & $(2.809 .762)$ & $(822.775)$ & $(1.052 .641)$ & $(109.017)$ & $(580.589)$ & \multicolumn{2}{|c|}{$(4.794 .195)(5.374 .784)$} \\
\hline Votanti & 79.9 & 83.4 & 79.0 & 75.9 & 73.5 & 80.2 & 79.4 \\
\hline Non voto & 24.6 & 22.7 & 25.8 & 33.1 & 33.0 & 24.7 & 25.6 \\
\hline Voti validi (sindaco) & 75.4 & 77.3 & 74.2 & 66.9 & 67.0 & 75.3 & 74.4 \\
\hline Voti validi (lista) & 62.8 & 72.0 & 71.4 & 61.4 & 67.2 & 66.3 & 66.3 \\
\hline Voto per il solo sindaco & 12.6 & 5.3 & 2.8 & 5.5 & - & 9.0 & \\
\hline
\end{tabular}

Il non voto comprende astenuti, schede bianche e schede nulle. Nel caso dei 14 comuni siciliani, il non voto si riferisce alla scheda per l'elezione del sindaco (in tal modo il valore ottenuto è omogeneo a quello relativo agli altri comuni che fa riferimento, quanto alle schede non valide, al voto per il sindaco). 
TAB. 10. Partecipazione elettorale e non voto; modalità di voto (21 novembre 1993) (percentuali su elettori iscritti)

\begin{tabular}{|c|c|c|c|c|c|c|c|}
\hline & \multirow{2}{*}{$\begin{array}{l}\text { Nord } \\
\text { n. \% }\end{array}$} & \multirow{2}{*}{$\begin{array}{l}\text { Centro } \\
\text { n. \% }\end{array}$} & \multirow{2}{*}{$\begin{array}{l}\text { Sud } \\
\text { n. \% }\end{array}$} & \multicolumn{2}{|c|}{ Isole } & \multicolumn{2}{|c|}{ Italia } \\
\hline & & & & $\begin{array}{c}\text { Sardegna } \\
\text { n. } \%\end{array}$ & $\begin{array}{l}\text { Sicilia } \\
\text { n. } \%\end{array}$ & $\begin{array}{c}\text { Sicilia escl. } \\
\text { n. } \%\end{array}$ & $\begin{array}{c}\text { Sicilia incl. } \\
\text { n. } \%\end{array}$ \\
\hline \multicolumn{8}{|l|}{ comuni metropolitani: } \\
\hline & $(598.584)$ & $(2.317 .077)$ & $(879.237)$ & & $(565.379)$ & $(3.794 .898)$ & $(4.360 .277)$ \\
\hline \multicolumn{8}{|l|}{ Votanti } \\
\hline & 26.1 & 25.6 & 37.3 & & 31.3 & 28.4 & 28.8 \\
\hline Non voto & 73.9 & 74.4 & 62.7 & & 68.7 & 71.6 & 71.2 \\
\hline Voti validi (sindaco) & 62.5 & 55.5 & 53.2 & & 65.7 & 56.1 & 57.4 \\
\hline Voti validi (lista) & 11.4 & 18.9 & 9.5 & \multicolumn{3}{|c|}{ Voto per il solo sindaco } & \\
\hline Voto per il solo sindaco & (6) & (3) & (8) & & (2) & (17) & (19) \\
\hline comuni capoluogo: & $(1.278 .611)$ & $(2.441 .461)$ & $(1.511 .816)$ & & $(619.885)$ & $(5.231 .888)$ & $(5.851 .773)$ \\
\hline (Elettori) & 80.3 & 78.6 & 72.5 & & 73.6 & 77.2 & 76.9 \\
\hline Votanti & 24.5 & 25.4 & 32.0 & & 31.1 & 27.1 & 27.5 \\
\hline Non voto & 75.5 & 74.6 & 68.0 & & 68.9 & 72.9 & 72.5 \\
\hline Voti validi (sindaco) & 62.9 & 66.2 & 59.8 & & 66.2 & 58.9 & 59.7 \\
\hline Voti validi (lista) & 12.6 & 18.4 & 8.2 & & - & 14.0 & \\
\hline Voto per il solo sindaco & & & & & & & \\
\hline
\end{tabular}




\begin{tabular}{|c|c|c|c|c|c|c|c|}
\hline comuni non capoluogo: & $(31)$ & (7) & $(21)$ & (1) & $(20)$ & $(60)$ & $(80)$ \\
\hline (Elettori) & $(839.324)$ & $(181.635)$ & $(542.725)$ & $(23.630)$ & $(530.725)$ & \multirow{2}{*}{\multicolumn{2}{|c|}{$\begin{array}{cc}(1.587 .214) & (2.118 .039) \\
82.7 & 81.2\end{array}$}} \\
\hline Votanti & 86.3 & 83.2 & 76.9 & 83.4 & 77.0 & & \\
\hline Non voto & 18.8 & 22.1 & 27.6 & 21.0 & 29.2 & 22.2 & 24.0 \\
\hline Voti validi (sindaco) & 81.2 & 77.9 & 72.4 & 79.0 & 70.8 & 77.8 & 76.0 \\
\hline Voti validi (lista) & 74.2 & 71.9 & 69.0 & 70.0 & 70.5 & 72.1 & 71.7 \\
\hline Voto per il solo sindaco & 7.0 & 6.0 & 3.4 & 9.0 & - & 5.7 & \\
\hline \multicolumn{8}{|l|}{ totale: } \\
\hline & $(2.117 .935)$ & $(2.623 .096)$ & $(2.054 .541)$ & $(23.630)$ & $(1.150 .610)$ & \multicolumn{2}{|c|}{$(6.819 .202)(7.969 .812)$} \\
\hline $\begin{array}{l}\text { Elettori } \\
\text { Votanti }\end{array}$ & 82.6 & 78.8 & 73.6 & 83.4 & 75.2 & 78.5 & 78.0 \\
\hline & 22.2 & 25.1 & 30.8 & 21.0 & 30.2 & 25.9 & 26.6 \\
\hline Non voto & 77.8 & 74.9 & 69.2 & 79.0 & 69.8 & 74.1 & 73.4 \\
\hline Voti validi (sindaco) & 67.4 & 57.4 & 62.2 & 70.0 & 68.2 & 62.0 & 62.8 \\
\hline $\begin{array}{l}\text { Voti validi (lista) } \\
\text { Voto per il solo sindaco }\end{array}$ & 10.4 & 17.5 & 7.0 & 9.0 & - & 12.1 & \\
\hline
\end{tabular}

Il non voto comprende astenuti, schede bianche e schede nulle. Nel caso dei 22 comuni siciliani, il non voto si riferisce alla scheda per l'elezione del sindaco (in tal modo il valore ottenuto è omogeneo a quello relativo agli altri comuni che fa riferimento, quanto alle schede non valide, al voto per il sindaco). 
ТАВ. 11. Concentrazione del voto di lista e del voto per il sindaco (valori percentuali sul totale dei voti validi)

\begin{tabular}{|c|c|c|c|c|c|c|c|c|c|c|c|c|}
\hline & \multicolumn{6}{|c|}{6 giugno 1993} & \multicolumn{6}{|c|}{21 novembre 1993} \\
\hline & \multicolumn{2}{|r|}{ (a) } & \multicolumn{2}{|c|}{ (b) } & \multicolumn{2}{|c|}{ (a) $+(b)$} & \multicolumn{2}{|r|}{ (a) } & \multicolumn{2}{|c|}{ (b) } & \multicolumn{2}{|c|}{ (a) $+(b)$} \\
\hline & $\%$ & $\Sigma$ & $\%$ & $\Sigma$ & $\%$ & $\Sigma$ & $\%$ & $\Sigma$ & $\%$ & $\Sigma$ & $\%$ & $\Sigma$ \\
\hline (n) & \multicolumn{2}{|r|}{ (14) } & \multicolumn{2}{|c|}{ (98) } & \multicolumn{2}{|c|}{ (112) } & \multicolumn{2}{|c|}{ (19) } & \multicolumn{2}{|c|}{ (81) } & \multicolumn{2}{|c|}{ (99) } \\
\hline \multicolumn{13}{|c|}{ liste: } \\
\hline $1^{\circ}$ & 33.9 & 33.9 & 30.9 & 30.9 & 32.5 & 32.5 & 29.8 & 29.8 & 30.0 & 30.0 & 29.8 & 29.8 \\
\hline $2^{\circ}$ & 15.4 & 49.3 & 22.0 & 52.9 & 18.6 & 51.1 & 18.8 & 48.6 & 18.1 & 48.1 & 18.6 & 48.4 \\
\hline $3^{\circ}$ & 10.5 & 59.8 & 14.9 & 67.8 & 12.6 & 63.7 & 12.1 & 60.7 & 14.0 & 62.1 & 12.7 & 61.1 \\
\hline $4^{\circ}$ & 9.2 & 69.0 & 10.0 & 77.8 & 9.6 & 73.3 & 9.9 & 70.6 & 10.4 & 72.5 & 10.0 & 71.1 \\
\hline
\end{tabular}

candidature:

\begin{tabular}{rrrrrrrrrrrrr}
$1^{\circ}$ & 37.8 & 37.8 & 35.0 & 35.0 & 36.6 & 36.6 & 42.4 & 42.4 & 37.1 & 37.1 & 41.0 & 41.0 \\
$2^{\circ}$ & 25.9 & 63.7 & 24.7 & 59.7 & 25.4 & 62.0 & 30.1 & 72.5 & 22.1 & 59.2 & 27.9 & 68.9 \\
$3^{\circ}$ & 14.9 & 78.6 & 13.9 & 73.6 & 14.1 & 76.1 & 14.1 & 86.6 & 16.1 & 75.3 & 14.7 & 83.6 \\
$4^{\circ}$ & 9.6 & 88.2 & 7.8 & 81.4 & 8.8 & 84.9 & 7.3 & 93.9 & 10.2 & 85.5 & 8.1 & 91.7 \\
\hline
\end{tabular}

(a): comuni capoluogo.

(b): comuni non capoluogo.

nell'arena consiliare e una parallela e ben più consistente concentrazione del voto per la scelta del sindaco. Mentre a giugno la distanza fra liste di testa e candidature più votate era di quattro punti, a novembre supera gli undici punti. Nel caso delle candidature l'indice di bipolarismo si avvicina al $70 \%$ dei voti validi e supera l' $80 \%$ nella sommatoria delle prime tre. La concentrazione del voto sulle prime due liste resta invece al di sotto del $50 \%$, mentre la sommatoria delle prime quattro supera di poco il $70 \%$ dei voti validi. Sul risultato di novembre incide senz'altro l'accresciuto scarto fra numero medio di candidature e numero medio di liste concorrenti che si registra nella tornata autunnale (tab. 4). Avviene però ceteris paribus quanto a numero medio di candidature in lizza (che passa da 6,4 a 6,2: tab. 4) e rispecchia quindi piuttosto l'effetto di un processo di apprendimento delle prerogative del nuovo sistema elettorale da parte degli elettori.

Anche il grado di concentrazione del voto e le differenze che in proposito si riscontrano nelle due arene sono influenzati dalla grandezza demografica dei comuni. Nel passaggio estivo 
più che in quello autunnale, $\mathrm{i}$ comuni capoluogo presentano rispetto agli altri centri una maggior dispersione del voto nell'arena rappresentativa e una maggior concentrazione del voto nell'arena esecutiva, senza significativi scostamenti di carattere territoriale.

Quando dalla cornice aggregata dei risultati si «scende» alla distribuzione delle preferenze alle liste e ai candidati, il confronto fra le due arene deve necessariamente proseguire su binari distinti ${ }^{26}$.

I risultati dell'arena rappresentativa pongono anzitutto un interrogativo relativo al destino elettorale dei partiti tradizionali e reclamano, in secondo luogo, una ponderazione che consenta di contenere il bias metropolitano connesso alla distribuzione demografico-amministrativa dei comuni e di limitare l'effetto ottico che ne deriva.

Le tabb. 12 e 13 forniscono una risposta alla prima questione, presentando un riepilogo dei risultati che pone a confronto i risultati del giugno e del novembre 1993 con quelli delle elezioni politiche del 1992 e delle elezioni comunali precedenti, svoltesi (in una data compresa fra il 1988 e il 1991) con la vecchia legge elettorale. Le due tabelle non consentono confronti in senso verticale, fra un partito e l'altro, poiché recano valori percentuali calcolati in riferimento a un numero di comuni (indicato nelle tabelle) diverso da partito a partito ${ }^{27}$. Consentono invece confronti di riga da cui è possibile ricavare, caso per caso, significative informazioni di carattere diacronico.

I risultati segnalano anzitutto il tracollo elettorale dei due partiti attorno ai quali si sono formate le coalizioni di governo dell'ultimo decennio. Nella tornata di giugno, la DC perde oltre

${ }^{26} \mathrm{Si}$ potrebbe mantenere il parallelismo analitico fra le due arene attraverso un confronto fra percentuali di voto ottenute dai candidati e percentuali di voto ottenute dalle liste che ne sostenevano la candidatura. Tale confronto è però reso complesso dalla necessità di identificare e classificare tutte le liste (operazione non sempre possibile) e si risolverebbe in una conferma dell'esistenza di quote non trascurabili di elettorato propenso a muoversi con una certa libertà sulle due arene e ad esprimere eventualmente un «voto diviso», come lo scarto fra voti validi per il sindaco e voti validi di lista (tabb. 9 e 10) e i dati sulla concentrazione del voto nelle due arene (tab. 11) già hanno prefigurato.

${ }_{27} \mathrm{Vi}$ sono comprese anche alcune liste partitiche prive di contrassegno ufficiale. Il numero di liste considerate è quindi superiore, pur se di poco, al numero di liste utilizzate per costruire le tabb. 5 e 6 . La tab. 12, inoltre, fa riferimento a 122 casi anziché 112 poiché considera i dieci comuni siciliani con popolazione compresa fra i 10.000 e i 15.000 abitanti che a giugno hanno votato con le regole previste per $i$ comuni con oltre 15.000 abitanti. 
un terzo del proprio precedente elettorato municipale e il PSI quasi la metà. La flessione assume proporzioni ancora più consistenti nella tornata autunnale. Su una base di riferimento più ristretta (e quindi circoscritta probabilmente alle antiche zone di forza), DC e PSI raggiungono con fatica un livello di consensi pari, rispettivamente, al $40 \%$ e al $25 \%$ della loro forza precedente. Il verdetto delle urne riserva una sorte analoga ai partiti laici minori, di cui la tabella evidenzia soprattutto l'assai limitata presenza su basi autonome, mentre il PDS non va al di là di una sostanziale tenuta ${ }^{28}$.

Di questo svuotamento del tradizionale centro sistemico si avvantaggiano i partiti estremi dello schieramento partitico tradizionale e la Lega, ovvero le forze lontane da responsabilità di governo (sia a livello centrale sia a livello locale) e appena lambite dai contraccolpi della «sfida giudiziaria». Rifondazione comunista accresce il seguito elettorale raccolto alle politiche del 1992, soprattutto nel passaggio elettorale di giugno e grazie al risultato ottenuto nei centri urbani del Nord (a Torino e a Mi-

TAB. 12. Elezioni comunali del 6 giugno 1993. Comuni con oltre 15.000 abitanti $(122$ casi). Il voto per $i$ principali partiti presenti in Parlamento e confronto con le elezioni politiche del 1992 e le elezioni comunali precedenti

\begin{tabular}{|c|c|c|c|c|c|c|}
\hline \multirow{2}{*}{ Liste } & \multicolumn{2}{|c|}{ Comunali giugno 1993} & \multicolumn{2}{|c|}{ Politiche 1992} & \multicolumn{2}{|c|}{ Comunali precedenti } \\
\hline & \multicolumn{2}{|c|}{ n. comuni $\%$ voti validi } & \multicolumn{2}{|c|}{ n. comuni $\%$ voti validi } & \multicolumn{2}{|c|}{ n. comuni $\%$ voti valid } \\
\hline DC & 108 & 19.5 & 108 & 24.8 & 108 & 28.8 \\
\hline PDS & 73 & 15.5 & 73 & 16.5 & & \\
\hline $\mathrm{RC}$ & 90 & 8.5 & 90 & 6.2 & & \\
\hline PSI & 48 & 9.6 & 48 & 16.1 & 48 & 18.2 \\
\hline MSI-DN & 87 & 6.4 & 87 & 6.1 & 87 & 4.3 \\
\hline PRI & 27 & 7.4 & 27 & 6.1 & 26 & 8.1 \\
\hline PLI & 6 & 5.5 & 6 & 5.6 & 6 & 6.1 \\
\hline PSDI & 35 & 3.0 & 35 & 2.7 & 34 & 4.7 \\
\hline Lista Pannella & $\mathrm{la}$ & 3.2 & 1 & 1.5 & & \\
\hline Verdi & 21 & 3.5 & 21 & 3.6 & & \\
\hline Lega & 38 & 25.2 & 38 & 12.7 & 9 & 9.1 \\
\hline Rete & 49 & 4.9 & 42 & 3.5 & & \\
\hline
\end{tabular}

Fonte: Servizio elettorale del Ministero degli Interni: «riepilogo politico del voto»

28 In questo caso, evidentemente, il riferimento è al voto politico del 1992. Meno significativo è il confronto con le ultime elezioni comunali tenute col vecchio sistema elettorale, per il numero assai ridotto di casi. 
TAB. 13. Elezioni comunali del 21 novembre 1993. Comuni con oltre 15.000 abitanti $(99$ casi). Il voto per $i$ principali partiti presenti in Parlamento e confronto con le elezioni politiche del 1992 e le elezioni comunali precedenti

\begin{tabular}{|c|c|c|c|c|c|c|}
\hline \multirow{3}{*}{$\begin{array}{l}\text { Liste } \\
\text { DC }\end{array}$} & \multirow{2}{*}{\multicolumn{2}{|c|}{$\begin{array}{l}\text { Comunali giugno } 1993 \\
\text { n. comuni \% voti validi }\end{array}$}} & \multirow{2}{*}{\multicolumn{2}{|c|}{$\frac{\text { Politiche } 1992}{\text { n. comuni } \% \text { voti validi }}$}} & \multirow{2}{*}{\multicolumn{2}{|c|}{$\begin{array}{l}\text { Comunali precedenti } \\
\text { n. comuni } \% \text { voti validi }\end{array}$}} \\
\hline & & & & & & \\
\hline & 72 & 14.3 & 71 & 29.8 & 71 & 34.7 \\
\hline PDS & 60 & 18.2 & 60 & 17.5 & 5 & 13.1 \\
\hline $\mathrm{RC}$ & 73 & 6.7 & 73 & 5.8 & 8 & 5.4 \\
\hline PSI & 13 & 5.6 & 13 & 16.1 & 13 & 21.2 \\
\hline MSI-DN & 62 & 17.5 & 61 & 7.6 & 61 & 5.3 \\
\hline PRI & 10 & 4.9 & 10 & 5.9 & 10 & 7.2 \\
\hline PLI & 1 & 1.4 & 1 & 4.4 & 1 & 6.6 \\
\hline PSDI & 13 & 2.2 & 13 & 3.8 & 13 & 4.4 \\
\hline Lista Pannella & $11 \mathrm{a}$ & 3.1 & 3 & 2.8 & & \\
\hline Verdi & 35 & 6.7 & 35 & 4.0 & 3 & 2.7 \\
\hline Lega & 25 & 30.9 & 25 & 15.7 & 14 & 9.9 \\
\hline Rete & 36 & 8.0 & 31 & 5.8 & 2 & 2.0 \\
\hline
\end{tabular}

Fonte: Servizio elettorale del Ministero degli Interni: «riepilogo politico del voto».

lano, ad esempio, si piazza direttamente alle spalle della Lega, pur se con una distanza, rispettivamente, di dieci e di trenta punti, superando il PDS). Ma è sul fronte opposto che si registrano, nella tornata autunnale, i risultati più sorprendenti, a seguito dei successi riportati dal MSI-DN, partito di maggioranza relativa a Roma e a Napoli. La Lega, dal canto suo, raddoppia sia a giugno che a novembre, la percentuale di consensi ottenuta alle politiche del 1992.

Un diverso accostamento ai risultati dell'arena rappresentativa, questa volta sincronico e suscettibile di confronti sia di riga che di colonna, si ricava dalla tab. 14 . Tale tabella punta a limitare, per quanto possibile, le distorsioni indotte dallo squilibrato assortimento demografico dei comuni, senza peraltro poter neutralizzare gli effetti della loro diversa distribuzione territoriale. Se i dati per singolo partito vanno considerati, di conseguenza, con la dovuta cautela ${ }^{29}$, ne scaturisce un quadro che, soprattutto a livello di schieramenti, precisa e riorienta quanto emerso nelle tabb. 12 e 13.

${ }^{29}$ Ciò vale soprattutto nel caso della Lega, per la diversa incidenza dei comuni del Nord nelle due tornate di voto e nelle tre classi di comuni che determina gli altalenanti risultati leghisti riportati nella tab. 14. 
TAB. 14. Elezioni comunali del 6 giugno e del 21 novembre 1993. Riepilogo dei risultati per le liste nei comuni capoluogo di provincia, nei comuni non capoluogo e nei comuni maggioritari ( $\%$ sui voti validi)

\begin{tabular}{|c|c|c|c|c|c|c|}
\hline & \multicolumn{2}{|c|}{ Capoluoghi di prov. } & \multicolumn{2}{|c|}{ Com. non capoluogo } & \multicolumn{2}{|c|}{ Com. maggior } \\
\hline & I & II & I & II & I & II \\
\hline (n) & (14) & (19) & (108) & (80) & $(1.070)$ & $(325)$ \\
\hline PDS & 11.2 & 15.5 & 12.0 & 10.8 & 2.2 & 3.3 \\
\hline $\mathrm{RC}$ & 9.9 & 6.5 & 5.0 & 5.6 & 1.6 & 1.0 \\
\hline Rete & 4.5 & 4.3 & 1.9 & 2.6 & - & 0.2 \\
\hline Verdi & 2.5 & 5.4 & 0.8 & 1.5 & - & 0.1 \\
\hline $\begin{array}{l}\text { Miste di sinistra } \\
\text { (Sinistra) }\end{array}$ & $\begin{array}{r}0.3 \\
(28.4)\end{array}$ & $\begin{array}{r}6.5 \\
(32.2)\end{array}$ & $\begin{array}{r}1.2 \\
(20.9)\end{array}$ & $\begin{array}{r}8.4 \\
(28.9)\end{array}$ & $\begin{array}{r}7.3 \\
(111)\end{array}$ & $\begin{array}{r}19.7 \\
(24.3)\end{array}$ \\
\hline PSI & 1.0 & 0.5 & 6.4 & 3.2 & 1.0 & 0.8 \\
\hline PRI & 0.4 & - & 2.1 & 0.9 & - & - \\
\hline $\begin{array}{l}\text { PSDI } \\
\text { («vecchia» area intermedia) }\end{array}$ & $\begin{array}{l}0.5 \\
(1.9)\end{array}$ & $\begin{array}{l}1.2 \\
(1.7)\end{array}$ & $\begin{array}{c}2.3 \\
(10.8)\end{array}$ & $\begin{array}{l}0.8 \\
(4.9)\end{array}$ & $(\overline{1.0})$ & $(\overline{0})$ \\
\hline Alleanza/Patto & & 6.7 & & 7.1 & & 1.8 \\
\hline $\begin{array}{l}\text { Lista Pannella } \\
\text { («nuova» area intermedia) }\end{array}$ & $\overline{(-)}$ & $\begin{array}{l}1.6 \\
(8.3)\end{array}$ & $\begin{array}{l}0.1 \\
(0.1)\end{array}$ & (7.1) & & (1.8) \\
\hline $\mathrm{DC}$ & 13.3 & 9.9 & 24.7 & 14.4 & 18.7 & 8.2 \\
\hline Miste di centro* & 0.6 & 5.3 & 2.5 & 8.9 & 8.4 & 25.1 \\
\hline PLI & - & 0.2 & 0.5 & 0.1 & - & - \\
\hline Unione di Centro & & 1.7 & & 0.3 & & 0.3 \\
\hline (Centro) & (13.9) & (17.1) & $(27.7)$ & $(23.7)$ & $(27.1)$ & $(33.6)$ \\
\hline $\operatorname{Lega}^{\star \star}$ & 25.2 & 7.3 & 4.5 & 14.5 & 6.7 & 8.4 \\
\hline Miste di destra & 2.2 & 0.6 & & & - & 0.2 \\
\hline MSI-DN & 5.0 & 18.0 & 6.2 & 6.1 & 1.7 & 1.6 \\
\hline (Destra) & $(5.0)$ & $(20.2)$ & $(6.2)$ & (6.7) & (1.7) & (1.8) \\
\hline
\end{tabular}

* Comprende «Coalizioni di area governativa».

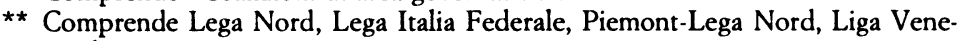
ta-Lega Nord.

I: tornata elettorale del 6 giugno 1993.

II: tornata elettorale del 21 novembre 1993.

Il tracollo elettorale della DC, ad esempio, viene in parte ridimensionato. Nonostante il forte calo subito nella tornata autunnale in tutte e tre le classi di comuni, la DC mantiene nei centri non-capoluogo e nei comuni maggioritari il suo precedente primato, pur se con un margine più risicato. Ciò vale anche per lo schieramento di centro, le cui liste subiscono una 
TAB. 15. Sindaci eletti al primo turno e loro sostegno politico-elettorale

\begin{tabular}{|c|c|c|c|c|c|c|c|c|}
\hline & \multicolumn{2}{|c|}{ Nord } & \multicolumn{2}{|c|}{ Centro } & \multicolumn{2}{|c|}{ Sud } & \multicolumn{2}{|c|}{ Italia } \\
\hline & I & II & & II & I & II & I & II \\
\hline Lega & & 1 & & & & & & 1 \\
\hline Alleanze di «progresso» & & & 1 & & 1 & & 2 & \\
\hline Sinistra «con nemici a sinistra» & 1 & & 1 & & 1 & & 3 & \\
\hline Liste eterogenee & & & & & 1 & 1 & 1 & 1 \\
\hline Indipendenti & & & & & 1 & & 1 & \\
\hline Totale & 1 & 1 & 2 & & 4 & 1 & 7 & 2 \\
\hline
\end{tabular}

I: tornata elettorale del 6 giugno 1993.

II: tornata elettorale del 21 novembre 1993.

sconfitta che non appare però una débâcle. Se si tiene presente che le liste dell'area intermedia, sia «vecchia» che «nuova», nel loro ondeggiare fra sinistra e centro hanno finito con l'aggregarsi più a quest'ultimo che alla prima ${ }^{30}$, lo schieramento di centro oltrepassa nei comuni non capoluogo la soglia del $30 \%$. Lo schieramento di sinistra, dal canto suo, nonostante la generalizzata crescita di consensi registrata fra giugno e novembre supera tale soglia soltanto in novembre nei comuni capoluogo (38\%). Al suo interno, le liste del PDS si assicurano fra il $10 \%$ e il $15 \%$ dei voti validi nei comuni maggiori, ma raccolgono in media, anche per la loro sporadica presenza, fra il $2 \%$ e il $3 \%$ dei voti nei comuni maggioritari (dove, nella tornata autunnale, si segnala il successo delle liste miste di sinistra). La tab. 14 colloca in una diversa prospettiva anche il risultato delle liste di destra. La forza di questo schieramento è largamente al di sotto del $10 \%$ nei comuni non capoluogo, dove peraltro il MSI-DN non ha mancato di cogliere alcuni successi nell'arena esecutiva, e nei comuni maggioritari. Il successo ottenuto a Roma e a Napoli in novembre fa invece del MSI-DN il partito di maggioranza nei capoluoghi di provincia, proiettando la destra al $20 \%$ dei consensi.

${ }^{30}$ Ciò vale, peraltro, soprattutto negli sviluppi successivi alle elezioni locali autunnali e in particolare, dopo la rottura fra i Popolari per la Riforma e Alleanza democratica, per le «nuova» area intermedia della tab. 14. 
Le distribuzioni del voto alle liste fin qui esaminate non sono molto indicative della distribuzione dei seggi a livello di consiglio. Sul versante dell'arena esecutiva, infatti, il voto del primo turno risulta decisivo soltanto in una piccola minoranza di casi (pari al 5\% dei comuni non-capoluogo: tab. 15). In tutti gli altri, il primo turno seleziona i candidati ammessi al ballottaggio e definisce così il profilo politico dei singoli scontri binari, rinviando al loro risultato l'attribuzione dei seggi alle liste.

\section{La logica del ballottaggio}

Quali candidati sono stati ammessi al ballottaggio? e quali hanno avuto maggior successo? Si è trattato di candidati appoggiati da un solo partito o sostenuti invece da un cartello di for$z e$ ? e in quanti casi (e quali) è stato eletto sindaco il candidato giunto secondo al primo turno? A quali scontri politici e coalizionali, infine, hanno messo capo i duelli binari per l'elezione dei sindaci? e con quale frequenza ed esiti complessivi?

Rispondere a queste domande consente di descrivere la struttura e le condizioni del turno di ballottaggio e di formulare quindi ipotesi di spiegazione degli orientamenti e delle logiche del voto e della capacità di aggregazione dimostrata da candidati e schieramenti.

La tab. 16 illustra un primo aspetto strutturale del ballottaggio: l'articolazione del sostegno dei candidati che vi hanno preso parte. Il principale elemento che se ne trae è indubbiamente il generalizzato calo dei candidati a sostegno monopartitico. Scomputando dal totale l'incidenza dei candidati leghisti (unica «famiglia» di candidati sempre e comunque monopartitica), la percentuale dei candidati ammessi al ballottaggio sulla base di un sostegno monopartitico passa da quasi la metà a circa un quarto. Crescono invece (dal $32.5 \%$ al $44.7 \%$ del totale) i candidati sostenuti da una coalizione di liste. Un andamento diacronico di questo tipo segnala l'emergere di una logica di schieramento e indica un processo di apprendimento da parte degli attori. Ad esso è correlato un secondo aspetto strutturale: il minor ricorso all'estensione delle alleanze fra il primo e il secondo turno prevista dalla legge elettorale (tab. 17). A giugno il ricombinarsi delle alleanze interessa infatti oltre un terzo dei comuni non capoluogo (nonché il comune di Vercelli), più della metà dei quali nel Mezzogiorno. A dicembre il fenomeno di- 
TAB. 16. L'articolazione del sostegno dei candidati ammessi al ballottaggio

\begin{tabular}{|c|c|c|c|c|c|c|c|c|c|c|c|c|c|c|c|c|c|c|}
\hline & \multicolumn{4}{|c|}{ Nord } & \multicolumn{3}{|c|}{ Centro } & \multicolumn{3}{|c|}{ Sud } & \multicolumn{2}{|c|}{ Sardegna } & \multicolumn{6}{|c|}{ Italia } \\
\hline & \multicolumn{2}{|c|}{ (a) } & \multicolumn{2}{|c|}{ (b) } & (a) & \multicolumn{2}{|c|}{ (b) } & (a) & \multicolumn{2}{|c|}{ (b) } & \multicolumn{2}{|c|}{ (b) } & \multicolumn{2}{|c|}{ (a) } & \multicolumn{2}{|c|}{ (b) } & \multicolumn{2}{|c|}{ (a) $+(b)$} \\
\hline & n. & $\%$ & $\mathrm{n}$. & $\%$ & n. $\%$ & $\mathrm{n}$. & $\%$ & n. $\%$ & $\mathrm{n}$. & $\%$ & n. & $\%$ & n. & $\%$ & $\mathrm{n}$. & $\%$ & n. & $\%$ \\
\hline $\begin{array}{l}20 \text { giugno 1993: } \\
\text { (n. comuni) }\end{array}$ & (8) & & (17) & & (4) & $(21)$ & & & (37) & & (4) & & (12) & & (79) & & (91) & \\
\hline $\begin{array}{l}\text { Sostegno } \\
\text { monopartitico }\end{array}$ & 8 & 50.0 & 27 & 79.4 & 450.0 & 18 & 42.9 & & 34 & 45.9 & & & 12 & 50.0 & 79 & 50.0 & 91 & 50.0 \\
\hline $\begin{array}{l}\text { Sostegno di una } \\
\text { coalizione di liste }\end{array}$ & 6 & 37.5 & 5 & 14.7 & 225.0 & 16 & 38.1 & & 19 & 25.7 & & 100.0 & 8 & 33.3 & 48 & 30.4 & 56 & 30.8 \\
\hline $\begin{array}{l}\text { Sostegno di una } \\
\text { lista di coalizione }\end{array}$ & 2 & 12.5 & 2 & 5.9 & 225.0 & 8 & 19.0 & & 21 & 28.4 & & & 4 & 16.7 & 31 & 19.6 & 35 & 19.2 \\
\hline (n. ammessi) & (16) & & (34) & & (8) & (42) & & & (74) & & (8) & & (24) & & (158) & & (182) & \\
\hline $\begin{array}{l}\text { novembre-dicembre } \\
\text { (n. comuni) }\end{array}$ & (6) & & $(30)$ & & (3) & (7) & & (8) & (20) & & (1) & & (17) & & (60) & & (77) & \\
\hline $\begin{array}{l}\text { Sostegno } \\
\text { monopartitico }\end{array}$ & 4 & 33.3 & 32 & 53.3 & & 2 & 14.3 & 425.0 & 18 & 45.0 & & & 8 & 23.5 & 52 & 44.8 & 60 & 40.0 \\
\hline $\begin{array}{l}\text { Sostegno di una } \\
\text { coalizione di liste }\end{array}$ & 8 & 66.7 & 21 & 35.0 & 6100.0 & 11 & 78.6 & 743.75 & 10 & 25.0 & 1 & 50.0 & 21 & 61.8 & 43 & 37.1 & 64 & 42.7 \\
\hline $\begin{array}{l}\text { Sostegno di una } \\
\text { lista di coalizione }\end{array}$ & & & 7 & 11.7 & & 1 & 7.1 & 531.25 & 12 & 30.0 & 1 & 50.0 & 5 & 14.7 & 21 & 18.1 & 26 & 17.3 \\
\hline (n. ammessi) & (12) & & $(60)$ & & (6) & (14) & & (16) & (40) & & (2) & & (34) & & (116) & & (150) & \\
\hline
\end{tabular}
(a): comuni capoluogo
(b): comuni non capoluogo 
TAB. 17. Dal primo al secondo turno: l'estensione delle alleanze elettorali

\begin{tabular}{|c|c|c|c|c|c|}
\hline & Nord & Centro & Sud & Sardegna & Italia \\
\hline \multicolumn{6}{|l|}{ giugno: } \\
\hline $\begin{array}{l}\text { Alleanze «di progresso» } \\
\text { PDS } \\
\text { Sinistra «con nemici a sinistra» } \\
\text { PRI } \\
\text { Area laico-socialista } \\
\text { DC } \\
\text { Coalizioni di centro } \\
\text { Altri }\end{array}$ & $\begin{array}{l}3 \\
1 \\
1 \\
1\end{array}$ & $\begin{array}{l}1 \\
3 \\
3 \\
1 \\
1 \\
4 \\
2\end{array}$ & $\begin{array}{l}2 \\
4 \\
3 \\
1 \\
1 \\
6 \\
5 \\
3\end{array}$ & 1 & $\begin{array}{r}3 \\
10 \\
8 \\
1 \\
2 \\
11 \\
7 \\
3\end{array}$ \\
\hline $\begin{array}{l}\text { tot. } \\
\text { (n) }\end{array}$ & $\begin{array}{c}6 \\
(5)\end{array}$ & $\begin{array}{c}14 \\
(12)\end{array}$ & $\begin{array}{c}24 \\
(19)\end{array}$ & $\begin{array}{c}1 \\
(1)\end{array}$ & $\begin{array}{c}45 \\
(37)\end{array}$ \\
\hline \multicolumn{6}{|l|}{ novembre: } \\
\hline $\begin{array}{l}\mathrm{RC} \\
\text { Alleanze «di progresso» } \\
\text { PDS } \\
\text { Coalizioni di centro }\end{array}$ & & $\begin{array}{l}1 \\
1 \\
1\end{array}$ & $\begin{array}{l}2 \\
1\end{array}$ & 1 & $\begin{array}{l}2 \\
2 \\
2 \\
1\end{array}$ \\
\hline $\begin{array}{l}\text { tot. } \\
\text { (n) }\end{array}$ & & $\begin{array}{c}3 \\
(2)\end{array}$ & $\begin{array}{c}3 \\
(3)\end{array}$ & $\begin{array}{c}1 \\
(1)\end{array}$ & $\begin{array}{c}7 \\
(6)\end{array}$ \\
\hline
\end{tabular}

venta del tutto residuale e forse non solo per l'estensione «preventiva» delle alleanze connessa al diffondersi delle candidature di coalizione, ma anche per una maggior cautela degli attori di fronte a un elettorato dimostratosi assai poco disposto ad assecondare ordini di scuderia.

Il carattere variegato delle alleanze (si torni alla tab. 8) e la diversa articolazione del sostegno ai candidati ammessi al ballottaggio (tab. 16) rende problematica la definizione del sostegno politico di questi ultimi e impone una semplificazione delle molte sfumature presenti. Lo schema riportato nella tab. 18 riaggrega tali sfumature in un più limitato, ma significativo, numero di classi, riducendo a quattro gli schieramenti (Lega, sinistra, centro, destra), cui va ad aggiungersi la categoria residuale degli «altri».

Su questa base, la successiva tab. 19 reca la distribuzione dei candidati ammessi e di quelli eletti. Il quantum di presenza dei candidati delle diverse «famiglie», influenzato com'è dall'assortimento dei comuni (si consideri in particolare il numero e l'incidenza dei candidati leghisti), non è molto indicativo. Vale 
TAB. 18. Schema di aggregazione delle candidature monopartitiche e delle candidature sostenute da una coalizione di lista o da una lista di coalizione nelle classi Lega, sinistra, centro e destra

\begin{tabular}{lll}
\hline Classi & $\begin{array}{l}\text { Candidature } \\
\text { monopartitiche }\end{array}$ & $\begin{array}{l}\text { Candidature sostenute da una coalizione } \\
\text { di liste o da una lista di coalizione }\end{array}$ \\
\hline LEGA & $\begin{array}{l}\text { Lega nord } \\
\text { Lega lombarda } \\
\text { Piemont/Lega nord } \\
\text { Liga Veneta/Lega nord }\end{array}$ & \\
& $\begin{array}{l}\text { Rifondazione comunista } \\
\text { Rete } \\
\text { Verdi }\end{array}$ & $\begin{array}{l}\text { Sinistra antagonista } \\
\text { Alleanze «di progresso» } \\
\text { PDS }\end{array}$ \\
& Sinistra «con nemici a sinistra» \\
CENTRO & $\begin{array}{l}\text { PSI } \\
\text { PRI }\end{array}$ & Area laica e/o socialista \\
& PSDI & Coalizioni di centro \\
& DC & \\
& Popolari per la riforma & \\
& PLI & \\
DESTRA & MSI & Alleanze di area MSI-DN \\
\hline
\end{tabular}

la pena tuttavia segnalare l'assottigliata presenza di candidati centristi nel ballottaggio di dicembre, nonostante il maggior numero di candidature centriste di coalizione (tab. 8) e la relativa «tenuta» delle liste di centro nell'arena rappresentativa (tab. 14). Il fenomeno, oltre alla evidente disaffezione dell'elettorato nei confronti dei partiti di centro, sembra dipendere quindi anche da un deficit di offerta dell'area mediana nell'arena esecutiva, risoltosi in un'accresciuta competitività dei candidati di destra $^{31}$.

Più significativo del quantum di presenza è il rendimento degli ammessi, ovvero la loro percentuale di successo. È qui, ad esempio, che il declino del centro si manifesta in tutta la sua evidenza. I (pochi) candidati centristi si segnalano per il loro assai modesto rendimento, soprattutto al ballottaggio del 5 dicembre in cui, alla stregua di veri e propri candidati-cuscinetto, si affermano tre sole volte su 38 . Anche la Lega, a tutt'altri li-

${ }^{31}$ Esemplare in tal senso il caso di Roma, dove, per indisponibilità degli interessati, l'area intermedia non è riuscita a contrapporre a quella di Fini una propria candidatura di spicco. 
velli di rendimento, registra nel ballottaggio autunnale una battuta d'arresto, che ne evidenzia una vulnerabilità forse inaspettata. I (molto numerosi) candidati dello schieramento di sinistra sono vincenti invece due volte su tre in entrambe le occasioni, il che consente loro di conquistare oltre la metà dei municipi. In discesa, infine, appare il rendimento dei candidati di destra, a fronte però di una maggior presenza al turno di ballottaggio e quindi di un accresciuto livello di competitività.

I dati sul rendimento delle diverse «famiglie» di candidati al turno di ballottaggio non dicono ancora molto sulle effettive condizioni politiche dei singoli scontri binari. La loro disaggregazione per tipo di confronto, con indicazione della relativa frequenza e, con punteggi a volte calcistici a volte rugbystici, dell'esito finale, è presentata nella tab. 20 (cfr. anche la tab. 21 che ne sistematizza le informazioni in un più sintetico quadro riassuntivo).

Il turno di ballottaggio configura anzitutto un quadro politico assai articolato. Delle possibili combinazioni fra $i$ quattro schieramenti hanno corso tutte le alternative salvo la contrapposizione fra candidati leghisti e candidati di destra. In alcuni casi il ballottaggio contrappone candidati appartenenti allo stesso campo (laici contro DC nell'area di centro; sinistra-centro contro sinistra antagonista nell'area di sinistra, come nel caso di Torino, indicato sul momento come caso esemplare per il tipo di sostegno raccoltosi intorno alla candidatura di Castellani in contrapposizione a Novelli (Bagnasco 1993), ma rimasto sostanzialmente senza seguito politico). I candidati «altri», infine, sfidano non senza successo (tab. 19) avversari di sinistra, di centro e di destra, riuscendo a conquistare anche due comuni capoluogo come Taranto (con Cito, «telepredicatore» alla testa della Lega d'azione meridionale) e Cosenza (con Mancini, uomo di sinistra sostenuto però da una coalizione atipica).

Le tabb. 20 e 21 confermano poi il negativo risultato dei candidati centristi, che colgono un solo successo nei comuni capoluogo (a Terni, con Ciaurro) e sono sconfitti con estrema facilità da avversari di qualsiasi colore. Desta interesse, inoltre, l'evoluzione del risultato dei duelli Lega-sinistra: a giugno i candidati della Lega hanno facilmente ragione dei loro avversari (e si lasciano sfuggire soltanto il comune di Belluno nonostante la posizione di testa conseguita al primo turno); a dicembre l'esito è assai più equilibrato e nei comuni capoluogo la sinistra prevale due volte su tre. A questa evoluzione non è estranea la loca- 
TAB. 19. Il rendimento dei candidati ammessi al ballottaggio

\begin{tabular}{|c|c|c|c|c|c|c|c|c|}
\hline & \multicolumn{3}{|c|}{20 giugno 1993} & \multicolumn{3}{|c|}{5 dicembre 1993} & \multicolumn{2}{|c|}{ sindaci } \\
\hline & ammessi & eletti & $\%$ & ammessi & eletti & $\%$ & n. & $\%$ \\
\hline (n) & & (91) & & & (75) & & (166) & \\
\hline Lega & 18 & 16 & 88.9 & 32 & 22 & 68.75 & 38 & 22.9 \\
\hline Sinistra & 72 & 48 & 66.7 & 61 & 40 & 65.6 & 88 & 53.0 \\
\hline Centro & 72 & 15 & 20.8 & 38 & 3 & 7.9 & 18 & 10.9 \\
\hline Destra & 6 & 6 & 100.0 & 14 & 5 & 35.7 & 11 & 6.6 \\
\hline Altri & 14 & 6 & 42.9 & 5 & 5 & 100.0 & 11 & 6.6 \\
\hline
\end{tabular}

lizzazione (relativamente periferica nella mappa elettorale leghista) delle amministrazioni andate alle urne nella tornata autunnale. Nella contrapposizione con la sinistra, tuttavia, la Lega manifesta anche due elementi di debolezza - l'isolamento competitivo e l'anodino profilo dei candidati - che nel passaggio elettorale di novembre-dicembre ne pregiudicano il rendimento e la rendono vulnerabile. Sia rispetto alle alleanze sia sul piano delle candidature, la sinistra si colloca invece in posizione di forza, in virtù della forza aggregativa messa in campo dal PDS e della disponibilità, soprattutto nelle principali città del Nord, di candidati dotati di un proprio autonomo appeal (Sansa a Genova, Cacciari a Venezia e, in uno scontro che non ha visto la Lega nel ruolo di protagonista, Illy a Trieste). Le tabb. 20 e 21 pongono in evidenza anche l'affermazione dei candidati di destra, i quali riescono a occupare lo spazio lasciato sguarnito dal centro e ad adattarsi con inaspettata prontezza al nuovo meccanismo elettorale. La destra, che pure sconfigge in giugno sei volte su sei la sinistra, in autunno non riesce però a conquistare né Roma né Napoli e perde anche a Trieste, conquistando invece centri di medie e piccole dimensioni (Latina e Chieti contro la sinistra, Benevento, Lanciano e Mondragone contro il centro).

Il turno di ballottaggio e i suoi esiti definiscono, infine, un quadro assai territorializzato delle polarità politiche prevalenti. Nei comuni del Nord il ballottaggio si gioca sulla contrapposizione fra candidati leghisti e candidati di sinistra, con un risultato che a dicembre è assai meno scontato che a giugno. Nei 
TAB. 20. La frequenza e l'esito degli scontri binari

\begin{tabular}{|c|c|c|c|c|c|c|}
\hline & & & $\begin{array}{l}20 \text { giugno } \\
\text { n. }\end{array}$ & $\begin{array}{l}1993 \\
\text { esito }\end{array}$ & $\begin{array}{c}5 \text { dicembr } \\
n .\end{array}$ & $\begin{array}{l}\text { e } 1993 \\
\text { esito }\end{array}$ \\
\hline \multicolumn{7}{|c|}{ comuni capoluogo: } \\
\hline $1^{\circ}$ & & $2^{\circ}$ & & & & \\
\hline Lega & vs. & Sinistra & 4 & $3-1$ & 1 & $1-0$ \\
\hline Sinistra & vs. & Lega & 2 & $0-2$ & 2 & $2-0$ \\
\hline Lega & vs. & Centro & & & 1 & $1-0$ \\
\hline Sinistra antag. & vs. & Sinistra-centro & 1 & $0-1$ & & \\
\hline Sinistra & vs. & Centro & 5 & $4-1$ & 5 & $5-0$ \\
\hline Sinistra & vs. & Destra & & & 4 & $4-0$ \\
\hline Destra & $v s$. & Sinistra & & & 1 & $0-1$ \\
\hline Centro & vs. & Destra & & & 1 & $0-1$ \\
\hline Sinistra & vs. & Altri & & & 1 & $0-1$ \\
\hline Centro & vs. & Altri & & & 1 & $0-1$ \\
\hline \multicolumn{3}{|l|}{ (n) } & \multicolumn{2}{|l|}{ (12) } & \multicolumn{2}{|c|}{ (17) } \\
\hline
\end{tabular}

comuni non capoluogo:

\begin{tabular}{|c|c|c|c|c|c|c|}
\hline $1^{\circ}$ & & $2^{\circ}$ & & & & \\
\hline Lega & $v s$ & Sinistra & 3 & 3.0 & 9 & $8-1$ \\
\hline Sinistra & $v s$ & Lega & & & 12 & $7-$ \\
\hline Lega & vs. & Centro & 6 & $6-0$ & 7 & \\
\hline Centro & vs. & Lega & 3 & $1-2$ & & \\
\hline Sinistra-centro & vs. & Sinistra antag. & 2 & $2-0$ & 1 & \\
\hline Sinistra & vs. & Centro & 26 & $26-0$ & 13 & 12 \\
\hline Centro & vs. & Sinistra & 13 & $3-10$ & 5 & \\
\hline Sinistra & vs. & Destra & 2 & $0-2$ & 4 & \\
\hline Destra & vs. & Sinistra & 4 & $4-0$ & 1 & \\
\hline Centro laico & vs. & Centro DC & 5 & $5-1$ & 1 & \\
\hline Centro DC & $v s$. & Centro laico & 3 & 3.0 & & \\
\hline Centro & $v s$. & Destra & & & 1 & \\
\hline Destra & $v s$. & Centro & & & 1 & \\
\hline Sinistra & $v s$. & Altri & 7 & $4-3$ & 1 & \\
\hline Centro & $v s$ & Altri & 2 & 1.0 & & \\
\hline Destra & vs. & Altri & & & 1 & \\
\hline Altri & vs. & Centro & 1 & $1-0$ & 1 & \\
\hline Altri & vs. & Altri & 2 & $2-0$ & & \\
\hline
\end{tabular}

(n)

(79)

(58)

comuni dell'Italia centrale, la larga maggioranza dei duelli pone di fronte un candidato di sinistra e un candidato centrista (di regola soccombente), mentre al Sud l'affermazione di alcuni candidati di destra e la diminuita presenza dei candidati di centro rendono più variegato un quadro che (nel passaggio autunnale) tende a radicalizzarsi. 
Le tabb. 20 e 21 consentono di cogliere anche un ultimo aspetto della struttura del ballottaggio: $i$ casi in cui si verifica un rovesciamento delle posizioni d'arrivo del primo turno e l'affermazione finale del candidato inizialmente secondo. Il fenomeno interessa, sia a giugno sia a dicembre, circa un quarto delle contese e merita di essere segnalato perché si produce principalmente a svantaggio, di nuovo, dei candidati del centro (di fronte a candidati di sinistra, ma anche contro esponenti della destra o della Lega) e anche di candidati della sinistra (di fronte a candidati leghisti). A trarne vantaggio sono invece principalmente candidati della sinistra (a giugno) e della Lega (a novembre), ma anche candidati di destra. In due sole occasioni (una volta a giugno, un'altra a dicembre) a compiere il «sorpasso» è il candidato centrista.

Questi andamenti sembrano contravvenire le aspettative di tipo centripeto spesso attribuite al doppio turno e invitano a un approfondimento ulteriore, che chiama in causa due variabili aggiuntive: il livello della partecipazione (e del non voto) e la forza d'attrazione dei candidati che si registrano, nel turno di ballottaggio, al variare della configurazione politica dello scon-

ТАВ. 21. Il rendimento delle quattro «famiglie» di candidati secondo la tipologia del ballottaggio

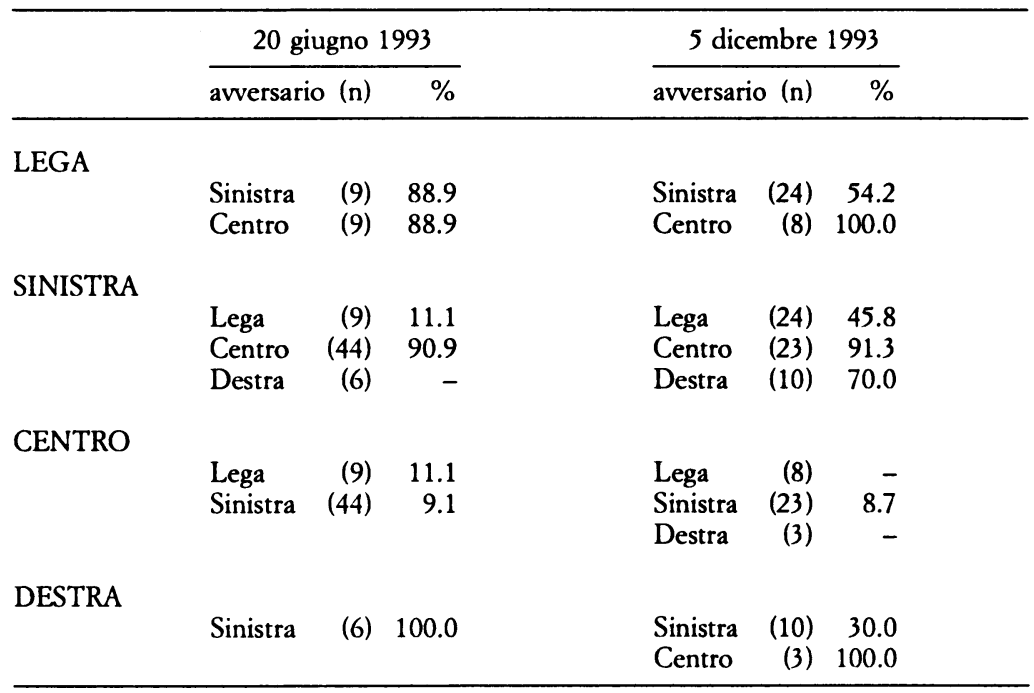


tro binario. Si tratta di variabili decisive negli esiti di ogni competizione a doppio turno e tanto più decisive quanto maggiore - come nel caso del doppio turno «chiuso» ai due candidati meglio piazzati qui in esame - è la forza costrittiva del meccanismo elettorale ${ }^{32}$. Come suggerisce l'esperienza comparata ${ }^{33}$, se ne possono ricavare indicazioni sulle modalità del «trasferimento» di voti da un turno all'altro e, quindi, eventuali elementi di spiegazione e ipotizzazione rispetto alle dimensioni della competizione e alle fratture competitive maggiormente salienti.

A questo scopo, la tab. 22 presenta, come prima misura della capacità aggregativa delle diverse «famiglie» di candidati, lo scarto fra voto di ballottaggio e voto di primo turno. Gli scarti percentuali sono riferiti ai diversi tipi di scontri binari, per ciascuno dei quali è stato calcolato anche l'andamento del non voto (astenuti, schede bianche e schede nulle). Com'era prevedibile, il turno di ballottaggio fa registrare, rispetto al primo turno, un non-voto aggiuntivo, che corrisponde a un disimpegno dettato da insoddisfazione o indifferenza rispetto alle alternative rimaste in campo ${ }^{34}$. Il fenomeno cui prestare principalmente attenzione è però il variare dell'incidenza di questo nonvoto aggiuntivo al variare della situazione competitiva. In proposito, si ricava dalla tab. 22 che la crescita del non-voto si fa più ingente in presenza di scontri binari cui prenda parte un candidato di centro. I candidati centristi, d'altro canto, raccolgono una percentuale di voti di gran lunga più modesta dei loro avversari (in particolare dei loro avversari leghisti) ${ }^{35}$ e mobilitano un consenso aggiuntivo assai contenuto.

32 Sartori ricorda in proposito come il doppio turno sia un sistema elettorale «a molte varianti», «troppo diversificato per consentire una sola conclusione generalizzante» rispetto agli effetti prodotti e possa essere classificato, «in chiave d'efficienza, a tre voci: forte, forte-debole, debole» $(1984,37)$.

${ }^{33}$ Il riferimento è evidentemente al caso della Quinta Repubblica. Sul punto, per l'analisi delle dinamiche competitive emerse nella fase di instaurazione del regime gollista, cfr. Bartolini (1981). Per un esame del funzionamento e degli effetti del doppio turno nelle diverse fasi della Quinta Repubblica cfr. Di Virgilio (1994).

${ }^{34} \mathrm{Si}$ spiega così l'elevato livello di non-voto aggiuntivo che si registra quando il ballottaggio mette di fronte duellanti appartenenti allo stesso campo. Uno scontro binario radicalizzato come il ballottaggio fra Rutelli e Fini a Roma ha indotto invece un (modesto) ciclo di mobilitazione elettorale e, quindi, un saldo negativo del non voto aggiuntivo.

${ }^{35}$ Deve considerarsi a parte l'esito complessivo degli scontri centro/destra, in cui i candidati di centro registrano addirittura un calo di consensi fra primo e secondo turno. Su tale risultato influisce in misura determinante il caso di Benevento, dove il candidato della coalizione di centro ha ottenuto 17.000 voti al primo turno e 11.000 al secondo. 
ТАВ. 22. Dal primo turno al ballottaggio: la forza d'aggregazione dei candidati (\% su elettori iscritti)

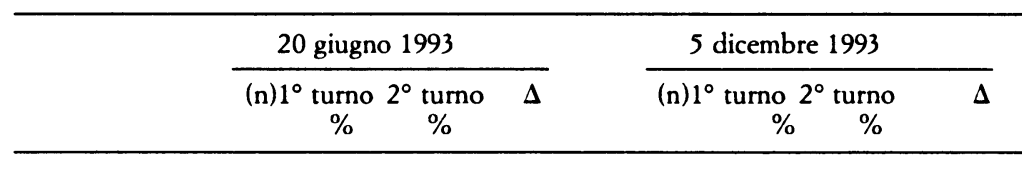

Lega vs. Sinistra

(9)

Lega

Sinistra

Non voto

Lega vs. Centro

Lega

Centro

Non voto

Sinistra vs. Centro (44)

Sinistra

Centro

Non voto

Sinistra vs. Destra (6)

Sinistra

Destra

Non voto

Centro vs. Destra

Centro

Destra

Altri

Sinistra vs. Sinistra (3)

Sinistra-centro

Sinistra antagonista

Non voto

Centro vs. Centro

(8)

Centro laico

Centro DC

Non voto
$22.438 .0+15.6$

$27.929 .0+1.1$

$24.3 \quad 33.0+8.7$

(9)

$25.341 .7+16.4$

$20.2 \quad 25.8+5.6$

$20.432 .5+12.1$

$\begin{array}{ll}26.2 & 40.7+14.5 \\ 20.0 & 26.7+6.7 \\ 23.0 & 32.6+9.6\end{array}$

$21.729 .0+7.3$

$25.139 .8+14.7$

$24.4 \quad 31.2+6.8$
(24)

$\begin{array}{llr}22.4 & 33.3 & +10.9 \\ 28.2 & 38.1 & +9.9 \\ 22.4 & 28.6 & +6.2\end{array}$

(8)

$\begin{array}{rrr}34.0 & 46.1 & +12.1 \\ 16.5 & 23.9 & +7.4 \\ 18.2 & 30.0 & +11.8\end{array}$

(23)

$\begin{array}{llr}22.6 & 39.4 & +16.8 \\ 18.0 & 24.9 & +6.9 \\ 25.5 & 35.7 & +10.2\end{array}$

(10)

$\begin{array}{rrr}28.8 & 38.9 & +10.1 \\ 24.4 & 33.8 & +9.4 \\ 28.5 & 27.3 & -1.2\end{array}$

(3)

$\begin{array}{llr}25.6 & 23.3 & -2.3 \\ 21.9 & 48.3 & +26.4 \\ 21.7 & 28.4 & +6.7\end{array}$

(1)

$\begin{array}{rrr}32.6 & 36.4 & +3.8 \\ 25.3 & 37.5 & +12.2 \\ 20.3 & 26.1 & +5.8\end{array}$

(1)

$21.2 \quad 30.7+9.5$

$20.130 .9+10.8$

$26.9 \quad 38.4+11.5$
$18.3 \quad 47.1+28.8$

$\begin{array}{lll}15.1 & 15.8+0.7\end{array}$

$\begin{array}{lll}19.7 & 37.1+17.4\end{array}$

Al turno di ballottaggio sembra prodursi insomma un quadro in cui l'elettore di centro, una volta privato dei propri candidati (eliminati dopo il primo turno), si «riposiziona» con maggiore facilità di altri elettori e tende quindi a «trasferire» il 
proprio voto piuttosto che ad astenersi o annullare la scheda. In assenza del proprio candidato, l'elettore di sinistra, quello leghista e quello di destra sembrano invece più propensi a defilarsi (non voto) che a scegliere sulla base delle alternative disponibili. Quando lo fanno, peraltro, «trasferiscono» solo in piccola misura il proprio voto in direzione dei candidati di centro. Dal passaggio estivo al passaggio autunnale si registra inoltre una maggior consistenza quantitativa dei fenomeni appena segnalati.

Questo insieme di fenomeni sembra indicare il manifestarsi di un processo di radicalizzazione dell'elettorato e lascia ipotizzare la presenza di un «trasferimento» delle preferenze di voto fra primo e secondo turno per segmenti non continui. Se ne potrebbe inferire - l'ipotesi va precisata meglio, ma potrà essere provata nei prossimi ravvicinati appuntamenti elettorali l'insorgere di una inedita frattura competitiva, una frattura fra «vecchio» (l'ancien régime rappresentato in primo luogo dai candidati centristi) e «nuovo» (ciò che è più lontano dal «vecchio»), la quale, al di là di ogni sua fondatezza sostantiva, taglia il tradizionale continuum destra/sinistra e induce «trasferimenti» di voto non tanto a favore del candidato più «vicino» quanto a vantaggio del candidato più «nuovo».

Come si è visto nella sezione destinata alla nuova legge elettorale, l'esito del ballottaggio retroagisce sui risultati dell'arena rappresentativa (tabb. 12, 13 e 14) e attraverso il meccanismo del premio maggioritario determina la composizione dei nuovi consigli comunali e la distribuzione dei seggi alle liste. I risultati di questa operazione rendono disponibile un implicito indicatore di rendimento delle strategie competitive adottate dagli attori: il confronto fra voti e seggi e, quindi, il grado di dis-rappresentanza delle diverse liste. Le tabb. 23 e 24 recano le percentuali dei voti e dei seggi per ciascuna lista partitica e per le liste «miste» (di sinistra, di centro e di destra) di schieramento, secondo una disaggregazione demografico-amministrativa e territoriale ${ }^{36}$.

${ }^{36}$ Come per le altre dimensioni prese in esame in questa sezione, anche l'analisi di quest'ultimo aspetto non tiene conto dei comuni siciliani, a causa del diverso sistema elettorale. 
ТАВ. 23. Rendimento delle strategie competitive: rapporto voti/seggi (giugno 1993)

\begin{tabular}{|c|c|c|c|c|c|c|c|c|}
\hline & \multicolumn{2}{|c|}{ Nord } & \multicolumn{2}{|c|}{ Centro } & \multirow{2}{*}{$\frac{\text { Sud }}{\text { (b) }}$} & \multirow{2}{*}{$\frac{\text { Sardegna }}{\text { (b) }}$} & \multicolumn{2}{|c|}{ Italia } \\
\hline & (a) & (b) & (a) & (b) & & & (a) & (b) \\
\hline (n) & (8) & (18) & (4) & (23) & (41) & (4) & (12) & (86) \\
\hline \multicolumn{9}{|l|}{$\mathrm{RC}$} \\
\hline$\%$ voti validi & 11.3 & 5.0 & 6.8 & 7.1 & 4.0 & 10.1 & 10.8 & 5.3 \\
\hline$\%$ seggi & 4.8 & 1.2 & 0.7 & 5.8 & 1.9 & 10.8 & 3.6 & 3.2 \\
\hline \multicolumn{9}{|l|}{ Rete } \\
\hline $\begin{array}{l}\% \text { voti validi } \\
\% \text { seggi }\end{array}$ & 4.1 & 0.9 & 1.5 & 1.4 & 1.2 & - & 3.7 & 1.3 \\
\hline \% seggi & & - & - & 0.4 & 0.8 & - & & \\
\hline \multicolumn{9}{|l|}{ Verdi } \\
\hline $\begin{array}{l}\% \text { votı validı } \\
\% \text { seggi }\end{array}$ & $\begin{array}{l}3.0 \\
2.2\end{array}$ & $\begin{array}{r}0.4 \\
-\end{array}$ & $\begin{array}{r}1.3 \\
-\end{array}$ & $\begin{array}{r}1.0 \\
-\end{array}$ & $\begin{array}{l}1.2 \\
0.8\end{array}$ & $\begin{array}{r}0.3 \\
-\end{array}$ & $\begin{array}{l}2.8 \\
1.6\end{array}$ & 0.4 \\
\hline \multicolumn{9}{|l|}{ PDS } \\
\hline$\%$ voti validi & 10.7 & 9.7 & 27.0 & 19.3 & 9.1 & 18.6 & 12.7 & 12.3 \\
\hline$\%$ seggi & 15.4 & 9.3 & 37.7 & 32.9 & 13.7 & 33.7 & 22.2 & 18.9 \\
\hline \multicolumn{9}{|c|}{ Miste di sinistra } \\
\hline $\begin{array}{l}\% \text { voti validi } \\
\% \text { seggi }\end{array}$ & - & $\begin{array}{l}1.6 \\
1.2\end{array}$ & - & $\begin{array}{r}0.9 \\
-\end{array}$ & $\begin{array}{l}1.1 \\
2.5\end{array}$ & - & - & $\begin{array}{l}1.1 \\
1.5\end{array}$ \\
\hline \multicolumn{9}{|l|}{ PSI } \\
\hline$\%$ voti validi & 1.0 & 4.1 & 2.0 & 5.7 & 7.5 & 10.7 & 1.2 & 6.5 \\
\hline$\%$ seggi & - & 0.1 & - & 7.3 & 7.1 & 10.8 & - & 6.1 \\
\hline \multicolumn{9}{|l|}{ DC } \\
\hline$\%$ voti validi & 10.4 & 19.2 & 17.5 & 21.5 & 28.3 & 20.4 & 11.2 & 24.4 \\
\hline \% seggi & 5.1 & 15.1 & 12.3 & 16.2 & 25.9 & 15.7 & 7.3 & 20.7 \\
\hline \multicolumn{9}{|c|}{ Miste di centro* } \\
\hline$\%$ voti validi & 0.8 & 0.4 & - & 3.9 & 1.5 & 1.9 & 0.7 & 1.9 \\
\hline$\%$ seggi & - & 0.3 & & 2.9 & 1.5 & - & - & 1.6 \\
\hline \multicolumn{9}{|l|}{ Lega } \\
\hline$\%$ voti validi & 32.0 & 24.9 & 1.8 & 1.5 & - & 0.4 & 28.3 & 5.3 \\
\hline \% seggi & 44.9 & 44.3 & - & - & - & - & 31.1 & 8.7 \\
\hline \multicolumn{9}{|l|}{ MSI-DN } \\
\hline $\begin{array}{l}\% \text { voti validi } \\
\% \text { seggi }\end{array}$ & $\begin{array}{l}4.2 \\
0.6\end{array}$ & $\begin{array}{r}4.1 \\
-\end{array}$ & $\begin{array}{l}6.6 \\
1.4\end{array}$ & $\begin{array}{l}3.9 \\
2.7\end{array}$ & $\begin{array}{l}8.1 \\
8.9\end{array}$ & $\begin{array}{r}3.6 \\
-\end{array}$ & $\begin{array}{l}4.9 \\
0.9\end{array}$ & $\begin{array}{l}0.1 \\
5.1\end{array}$ \\
\hline
\end{tabular}

* Comprende «Coalizioni di area governativa». 
ТАв. 24. Rendimento delle strategie competitive: rapporto voti/seggi (novembre-dicembre 1993)

\begin{tabular}{|c|c|c|c|c|c|c|c|c|c|}
\hline & & & $\mathrm{Ce}$ & & & & Sardegna & & alia \\
\hline & (a) & (b) & (a) & (b) & (a) & (b) & (b) & (a) & (b) \\
\hline (n) & (6) & (31) & (3) & (7) & (8) & (21) & (1) & (17) & (60) \\
\hline $\begin{array}{l}\text { RC } \\
\% \text { voti validi } \\
\% \text { seggi }\end{array}$ & $\begin{array}{l}7.4 \\
3.5\end{array}$ & $\begin{array}{l}6.3 \\
3.0\end{array}$ & $\begin{array}{l}6.8 \\
5.4\end{array}$ & $\begin{array}{l}5.4 \\
5.7\end{array}$ & $\begin{array}{l}6.9 \\
6.1\end{array}$ & $\begin{array}{l}6.9 \\
4.0\end{array}$ & $\begin{array}{l}7.5 \\
3.8\end{array}$ & $\begin{array}{l}7.0 \\
5.1\end{array}$ & $\begin{array}{l}6.4 \\
3.7\end{array}$ \\
\hline $\begin{array}{l}\text { Rete } \\
\% \text { voti validi } \\
\% \text { seggi }\end{array}$ & $\begin{array}{l}1.2 \\
0.4\end{array}$ & $\begin{array}{l}0.8 \\
1.0\end{array}$ & $\begin{array}{l}0.1 \\
0.5\end{array}$ & $\begin{array}{l}1.3 \\
0.6\end{array}$ & $\begin{array}{l}1.5 \\
0.1\end{array}$ & $\begin{array}{r}0.3 \\
-\end{array}$ & - & $\begin{array}{l}0.8 \\
0.1\end{array}$ & $\begin{array}{l}0.7 \\
0.7\end{array}$ \\
\hline $\begin{array}{l}\text { Verdi } \\
\% \text { voti validi } \\
\% \text { seggi }\end{array}$ & $\begin{array}{l}3.3 \\
4.3\end{array}$ & $\begin{array}{l}2.6 \\
1.8\end{array}$ & $\begin{array}{r}10.0 \\
7.7\end{array}$ & $\begin{array}{l}2.3 \\
0.6\end{array}$ & $\begin{array}{l}2.9 \\
1.0\end{array}$ & $\begin{array}{l}1.1 \\
0.7\end{array}$ & - & $\begin{array}{l}6.2 \\
3.4\end{array}$ & $\begin{array}{l}2.0 \\
1.2\end{array}$ \\
\hline $\begin{array}{l}\text { PDS } \\
\% \text { voti validi } \\
\% \text { seggi }\end{array}$ & $\begin{array}{l}20.9 \\
29.4\end{array}$ & $\begin{array}{r}9.0 \\
14.9\end{array}$ & $\begin{array}{l}17.8 \\
23.8\end{array}$ & $\begin{array}{l}17.2 \\
27.0\end{array}$ & $\begin{array}{l}14.4 \\
11.9\end{array}$ & $\begin{array}{l}13.4 \\
27.2\end{array}$ & $\begin{array}{r}13.1 \\
7.7\end{array}$ & $\begin{array}{l}17.6 \\
20.3\end{array}$ & $\begin{array}{l}11.4 \\
20.1\end{array}$ \\
\hline $\begin{array}{l}\text { Miste di sinistra } \\
\% \text { voti validi } \\
\% \text { seggi }\end{array}$ & $\begin{array}{l}5.0 \\
4.3\end{array}$ & $\begin{array}{l}8.9 \\
7.1\end{array}$ & $\begin{array}{l}3.8 \\
7.7\end{array}$ & $\begin{array}{l}6.8 \\
5.0\end{array}$ & $\begin{array}{l}10.3 \\
19.3\end{array}$ & $\begin{array}{l}6.3 \\
9.9\end{array}$ & $\begin{array}{r}21.8 \\
7.7\end{array}$ & $\begin{array}{r}6.0 \\
11.9\end{array}$ & $\begin{array}{l}8.0 \\
7.6\end{array}$ \\
\hline $\begin{array}{l}\text { PSI } \\
\% \text { voti validi } \\
\% \text { seggi }\end{array}$ & - & $\begin{array}{r}1.1 \\
-\end{array}$ & - & $\begin{array}{l}5.0 \\
3.8\end{array}$ & $\begin{array}{l}2.0 \\
0.3\end{array}$ & $\begin{array}{l}5.6 \\
3.4\end{array}$ & - & $\begin{array}{l}0.6 \\
0.1\end{array}$ & $\begin{array}{l}3.0 \\
1.6\end{array}$ \\
\hline $\begin{array}{l}\text { Alleanza/Patto } \\
\% \text { voti validi } \\
\% \text { seggi }\end{array}$ & $\begin{array}{l}5.4 \\
7.8\end{array}$ & $\begin{array}{l}7.0 \\
3.5\end{array}$ & $\begin{array}{l}5.0 \\
6.9\end{array}$ & $\begin{array}{l}3.0 \\
1.3\end{array}$ & $\begin{array}{r}7.6 \\
11.9\end{array}$ & $\begin{array}{l}7.0 \\
3.2\end{array}$ & $\begin{array}{r}7.1 \\
26.9\end{array}$ & $\begin{array}{l}5.9 \\
9.5\end{array}$ & $\begin{array}{l}6.5 \\
3.6\end{array}$ \\
\hline $\begin{array}{l}\text { DC } \\
\% \text { voti validi } \\
\% \text { seggi }\end{array}$ & $\begin{array}{l}3.4 \\
7.4\end{array}$ & $\begin{array}{r}11.0 \\
8.0\end{array}$ & $\begin{array}{l}12.4 \\
10.8\end{array}$ & $\begin{array}{l}16.4 \\
11.3\end{array}$ & $\begin{array}{l}9.9 \\
8.4\end{array}$ & $\begin{array}{r}15.4 \\
9.2\end{array}$ & $\begin{array}{r}16.8 \\
7.7\end{array}$ & $\begin{array}{l}9.3 \\
8.5\end{array}$ & $\begin{array}{r}13.1 \\
8.7\end{array}$ \\
\hline $\begin{array}{l}\text { Miste di centro } \\
\% \text { voti validi } \\
\% \text { seggi }\end{array}$ & $\begin{array}{l}9.4 \\
4.3\end{array}$ & $\begin{array}{l}4.8 \\
1.8\end{array}$ & $\begin{array}{l}2.0 \\
3.8\end{array}$ & $\begin{array}{r}9.5 \\
16.3\end{array}$ & $\begin{array}{l}6.0 \\
5.1\end{array}$ & $\begin{array}{r}9.9 \\
12.4\end{array}$ & - & $\begin{array}{l}5.2 \\
4.8\end{array}$ & $\begin{array}{l}6.9 \\
7.1\end{array}$ \\
\hline $\begin{array}{l}\text { Lega } \\
\% \text { voti validi } \\
\% \text { seggi }\end{array}$ & $\begin{array}{l}28.2 \\
32.5\end{array}$ & $\begin{array}{l}35.0 \\
55.0\end{array}$ & $\begin{array}{r}1.1 \\
-\end{array}$ & $\begin{array}{r}1.1 \\
-\end{array}$ & $\begin{array}{r}0.5 \\
-\end{array}$ & $\begin{array}{r}0.3 \\
-\end{array}$ & $\begin{array}{l}- \\
-\end{array}$ & $\begin{array}{r}8.0 \\
11.2\end{array}$ & $\begin{array}{l}19.2 \\
27.8\end{array}$ \\
\hline $\begin{array}{l}\text { MSI-DN } \\
\% \text { voti validi } \\
\% \text { seggi }\end{array}$ & $\begin{array}{l}4.1 \\
0.4\end{array}$ & $\begin{array}{r}2.9 \\
-\end{array}$ & $\begin{array}{l}29.1 \\
10.0\end{array}$ & $\begin{array}{l}7.4 \\
8.2\end{array}$ & $\begin{array}{l}20.0 \\
12.9\end{array}$ & $\begin{array}{l}13.4 \\
18.1\end{array}$ & $\begin{array}{r}4.1 \\
-\end{array}$ & $\begin{array}{r}19.9 \\
8.0\end{array}$ & $\begin{array}{l}6.9 \\
7.1\end{array}$ \\
\hline $\begin{array}{l}\text { Miste di destra } \\
\% \text { voti validi } \\
\% \text { seggi }\end{array}$ & $\begin{array}{l}1.9 \\
1.3\end{array}$ & $\begin{array}{r}0.4 \\
-\end{array}$ & $\begin{array}{r}3.7 \\
20.0\end{array}$ & $\begin{array}{l}2.2 \\
1.9\end{array}$ & $\begin{array}{l}1.2 \\
2.2\end{array}$ & $\begin{array}{r}0.2 \\
-\end{array}$ & - & $\begin{array}{l}2.5 \\
5.4\end{array}$ & $\begin{array}{l}0.6 \\
0.2\end{array}$ \\
\hline
\end{tabular}


Fra destrutturazione e processi di apprendimento

Come l'analisi condotta fin qui ha teso a dimostrare, l'impatto e gli effetti della nuova legge elettorale comunale sono difficilmente scindibili dal concomitante processo di destrutturazione partitica. Le nuove regole - e in particolare l'investitura diretta del sindaco a doppio turno «chiuso» - hanno enfatizzato alcuni aspetti del dealignment in atto, ed esso, a sua volta, ha influito sulle modalità di impiego delle nuove regole da parte degli attori. È quanto emerge dai principali risultati del voto e in particolare dallo stritolamento dei tradizionali partiti di centro, fulcro delle coalizioni di governo degli ultimi decenni e tessuto connettivo del sistema partitico, che si sono aggiudicati un numero limitatissimo di municipi. Il voto premia invece attori nuovi (la Lega) o prevalentemente d'opposizione (il PDS, in quanto fulcro di variegate e spesso vincenti aggregazioni di sinistra, e il MSI-DN), anche per questo meno centrali rispetto alla «questione giudiziaria».

Le prime applicazioni della nuova legge elettorale hanno tuttavia reso ugualmente evidenti i fattori competitivi maggiormente influenti sull'esito del voto. Si tratta, essenzialmente, della forza aggregativa dei singoli attori e della loro capacità di attivare una logica di schieramento, della qualità dei candidati alla carica di sindaco, della polarità politica e di schieramento definita dallo scontro binario di ballottaggio. Rispetto a questi fattori, gli attori si sono posizionati diversamente e hanno dimostrato capacità diverse di apprendimento. Le forze di centro e la Lega, ad esempio, hanno dimostrato una limitata forza d'aggregazione e carenze più o meno marcate sul versante delle candidature alla carica di sindaco. Ciò ne ha parzialmente penalizzato la performance elettorale, in particolare nell'arena esecutiva. Da entrambi i punti di vista, il PDS ha avuto la disponibilità di condizioni competitive assai favorevoli e forse difficilmente ripetibili. Ha potuto infatti contare, da un lato, su un margine di manovra accresciuto dalla diaspora dell'area intermedia e, dall'altro, sulla capacità di aggregare l'intero schieramento di sinistra, o larga parte di esso, attorno a candidati in alcuni casi particolarmente competitivi sia per estrazione sia per autonomo appeal elettorale. Analoga e inaspettata prontezza nell'adattarsi alle nuove regole e nel tentare di occupare uno spazio resosi improvvisamente (semi)vacante ha dimostrato, in presenza di più difficili condizioni di partenza, anche la destra 
missina che deve sostanzialmente a tale apprendimento (e a mosse indovinate quali la candidatura di Fini a Roma in assenza di un'adeguata offerta di centro) la propria affermazione.

Pur se confrontato a regole di voto nuove e più complesse delle precedenti, l'elettorato ha dimostrato di saper cogliere al volo la logica di fondo del nuovo meccanismo elettorale. L'impiego selettivo delle diverse modalità di espressione del voto, $i$ comportamenti differenziati di voto registrati nelle due arene, l'atteggiamento adottato al ballottaggio sono evidenti indizi di un rapido adattamento. Il comportamento degli elettori, com'era prevedibile, si è dimostrato particolarmente sensibile alla contrapposizione messa in campo dallo scontro binario di ballottaggio, adeguandovi livelli di partecipazione elettorale (e di non-voto) e percorsi di «trasferimento» del voto. Anziché produrre sequenze lineari e spostamenti per segmenti continui, magari con esiti centripeti, le scelte del turno di ballottaggio segnalano «trasferimenti» a carattere discontinuo che corrispondono, in questa fase, all'esigenza primaria di un sortez les sortants! e quindi a una radicalizzazione che insiste non necessariamente sull'asse destra/sinistra quanto su un più o meno malinteso continuum «vecchio»/«nuovo».

In che misura questi andamenti, cui si accompagna l'accentuata territorializzazione del voto e degli scontri binari di ballottaggio, siano suscettibili di stabilizzazione o rappresentino soltanto delle istantanee di un treno in corsa non è facile dire, anche perché essi forniscono un quadro comunque parziale. Come si è visto, i due passaggi elettorali in esame, pur coinvolgendo un insieme di comuni e di elettori per nulla esiguo, hanno interessato prevalentemente contesti urbani e metropolitani e l'analisi ha segnalato quanto il fattore demografico sia discriminante in termini di effetti della nuova legge elettorale e di impatto sui comportamenti degli elettori. Quel che però si può dire, come del resto è emerso dagli elementi di confronto fra tornata estiva e tornata autunnale presentati nel corso dell'analisi, è che tale evoluzione dipenderà in larga parte dal fattore tempo e dal combinarsi di fattori diversi: il se e il come della ricomposizione dell'area intermedia, la capacità degli attori vincenti di fissare il loro vantaggio, la capacità degli attori perdenti di selezionare strategie competitive più consone alle nuove regole, l'intersecarsi delle nuove fratture competitive («vecchio» vs. «nuovo») con le più antiche e tradizionali divisioni (l'asse destra/sinistra). 
Riferimenti bibliografici

Agosta, A. (1992), La formazione degli ordinamenti elettorali regionali e clocali nel sistema politico italiano, in Riccamboni (1992), pp. 115-192.

Bagnasco, A. (1993), Torino: una città che ricomincia dalla politica, in «Il Mulino», 4, pp. 727-734.

Barbera, A. (a cura di) (1993), Elezione diretta del sindaco del presidente della provincia del consiglio comunale e del consiglio provinciale. Commento alla legge 25 marzo 1993, n. 81, Rimini, Maggioli.

Bardi, L. e L. Morlino (1994), Italy: the promise of transformation, in R.S. Katz e P. Mair (a cura di), How parties organize: adaptation and change in party organization in Western democracies, Londra Beverly Hills, Sage.

Bartolini, S. (1981), Riforma istituzionale e sistema politico. La Francia gollista, Bologna, il Mulino.

Cammelli, M. (1993), Eletto dal popolo: il sindaco fra nuovo ruolo $e$ vecchi poteri, in «Il Mulino», 4, pp. 775-784.

Di Franco, G. e R. Gritti (1993), La «rivoluzione» nelle urne. Un'analisi dei risultati delle elezioni amministrative del 6 e del 20 giugno 1993 , in «Sociologia e ricerca sociale», 42 pp. 118-168.

Di Virgilio, A. (1992), Il rendimento dei sistemi elettorali a livello municipale e regionale in Francia, in Riccamboni (1992) cit., pp. 15. 53.

- (1994), Francia: doppio turno e Quinta Repubblica, in O. Massari e G. Pasquino (a cura di), Rappresentare e governare, Bologna, il Mulino.

Gambino, S. (a cura di) (1991), Sistemi elettorali e governo locale. Modelli europei a confronto, Roma, Edizioni delle Autonomie.

Giorgis, A. (1991), I referendum elettorali. Il «compromesso» $n$. 47/91, Torino, Giappichelli.

Istituto Nazionale di Statistica (1993), Popolazione legale, Roma, Istat.

Lanza, O. e R. Motta (1993), Catania: un vincitore senza maggioranza, in «Il Mulino», 4, pp. 754-763.

Riccamboni, G. (a cura di) (1992), Cittadini e rappresentanza in Europa, Milano, Angeli.

Sani, G. (1993), Milano: se il centro si frantuma, in «Il Mulino», 4, pp. 735-744.

Sartori, G. (1984), Le «leggi» sull'influenza dei sistemi elettorali, in «Rivista italiana di scienza politica», 1, pp. 3-40.

Vandelli, L. (1990), Ordinamento delle autonomie locali. Commento alla legge 8 giugno 1990, $n$. 142, Rimini, Maggioli.

Vassallo, S. (1993), Commento all'art. 7, in Barbera (a cura di) (1993), pp. 66-75.

Verzichelli, L. (1993), Siena: l'incertezza tra $i$ vecchio e il nuovo, in «Il Mulino», 4, pp. 745-753. 